Florida International University FIU Digital Commons

\title{
Transmission, Legitimation, and Adaptation: A Study of Western Lamas in the Construction of 'American Tibetan Buddhism'
}

Mariana Restrepo

Florida International University, marianarestrepos@hotmail.com

DOI: $10.25148 /$ etd.FI13041504

Follow this and additional works at: https://digitalcommons.fiu.edu/etd

\section{Recommended Citation}

Restrepo, Mariana, "Transmission, Legitimation, and Adaptation: A Study of Western Lamas in the Construction of 'American Tibetan Buddhism'" (2013). FIU Electronic Theses and Dissertations. 822.

https://digitalcommons.fiu.edu/etd/822 


\section{FLORIDA INTERNATIONAL UNIVERSITY}

Miami, Florida

TRANSMISSION, LEGITIMATION, AND ADAPTATION: A STUDY OF WESTERN LAMAS IN THE CONSTRUCTION OF 'AMERICAN TIBETAN BUDDHISM'

A thesis submitted in partial fulfillment of

the requirements for the degree of

MASTER OF ARTS

in

RELIGIOUS STUDIES

by

Mariana Restrepo 
To: $\quad$ Dean Kenneth G. Furton

College of Arts and Sciences

This thesis, written by Mariana Restrepo, and entitled Transmission, Legitimation, and Adaptation: A Study of Western Lamas in the Construction of 'American Tibetan Buddhism' having been approved in respect to style and intellectual content is referred to you for judgment.

We have read this thesis and recommend that it be approved

\begin{tabular}{rr}
\hline Steven Heine \\
\hline Albert Wuaku \\
\hline Nathan Katz, Major Professor
\end{tabular}

Date of Defense: March 28, 2013

This thesis of Marian Restrepo is approved.

Dean Kenneth G. Furton
College of Arts and Sciences

Florida International University, 2013 


\section{DEDICATON}

May all beings benefit. 


\section{ACKNOWLEDGMENTS}

I wish to thank the many people who made this thesis possible. First and foremost, I would like to thank Dr. Nathan Katz for his guidance and support throughout the years. His invaluable comments and contributions have shaped my academic development, for which I will always be indebted to him. I am grateful to Dr. Steven Heine for his intellectual guidance, his invaluable contributions and his unconditional support. To Dr. Albert Wuaku for teaching me the skills necessary to conduct ethnographic research, a central aspect of this thesis. I would also like to thank the Program in the Study of Spirituality at FIU and the Asian Studies program for generously funding my research.

I would also like to thank the lamas who were interviewed for this thesis, Lama John Makransky, Lama Willa Miller, Dr. Reggie Ray, and Lama Karma Chötso for allowing me the opportunity to talk to them and attend their retreats. I am especially thankful to Lama Karma Chötso for her guidance, support and encouragement. I am grateful to all the professors who throughout the years have shaped my academic development. While its impossible to name all, I would like to especially thank Professor Daniel Alvarez, Dr. Whitney Bauman, Dr. Laura Ogden, and Professor Michael Hettich, I want to thank my student colleagues for their support throughout this process. A special thanks to Daniella Vaclavik, Priyanka Ramlakhan, Kimberly Zwez, Shivani Bothra, and Nicholas Pearce for the many conversations that allowed me to shape my concept and ideas.

I am indebted to my friends Luke Connell, Damian Geddry, Kellie Powell, and Kimberly Zwez, for taking the time to read my chapters and for providing valuable 
feedback. I am especially grateful to Lama Karma (Justin Wall) for spending countless hours carefully reading my thesis, for his encouragement and unconditional support. I am also thankful to the Kagyu Shedrup Chöling sangha, especially to Shamelle Gonzalez, Johanna Santos, Tony Recio, Luciana Rodriguez and Adriana Zamora for encouraging me. Finally I would like to thank my family for always believing in me. 


\begin{abstract}
OF THE THESIS
TRANSMISSION, LEGITIMATION, AND ADAPTATION: A STUDY OF WESTERN

LAMAS IN THE CONSTRUCTION OF ‘AMERICAN TIBETAN BUDDHISM’
\end{abstract}

\author{
by
}

Mariana Restrepo

Florida International University, 2013

Miami, Florida

\title{
Professor Nathan Katz, Major Professor
}

This thesis presents a study of the role of western lamas within Tibetan Buddhism in America, arguing that the role of the lama is as an influential and central aspect in the development and transformation of the Tibetan Buddhist tradition in the west. This thesis argues how western lamas holding a position of authority act as a catalyst of change within their group and in the overall process of change and adaptation of the Tibetan Buddhist tradition in America, creating what may become 'American Tibetan Buddhism.' Three relevant areas regarding the role of the lama within the transforming tradition are identified: 1) the basis of authority of the lama, or how authority is obtained; 2) the use of such authority as a tool for change; and 3) transmission of the teachings and lineage. 


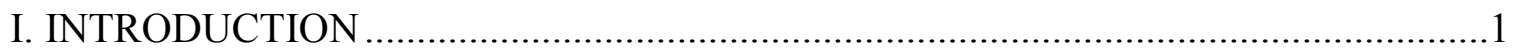

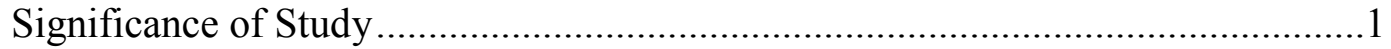

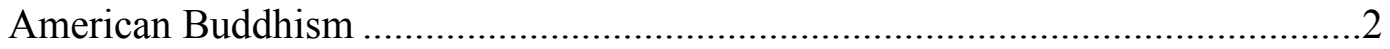

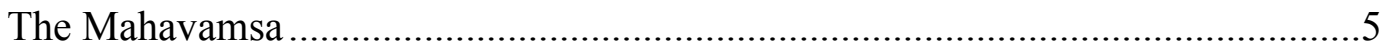

Tibetan Buddhism in America ..........................................................................

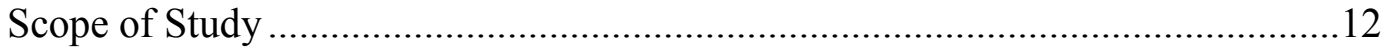

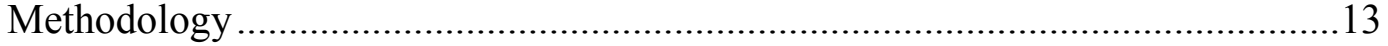

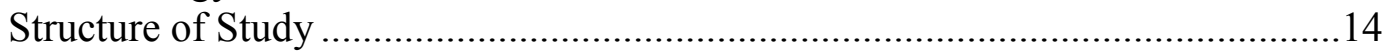

II. THE AMERICAN BUDDHIST LANDSCAPE: CATEGORIZING BUDDHISM IN

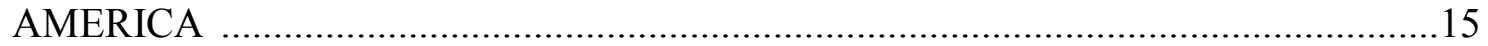

Two Buddhisms, Three Buddhisms, Too Many Buddhisms ................................15

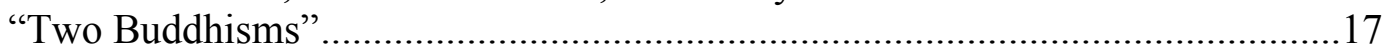

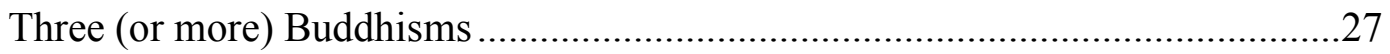

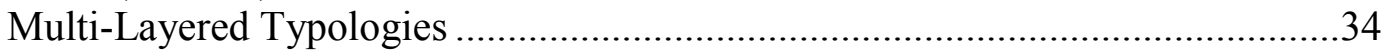

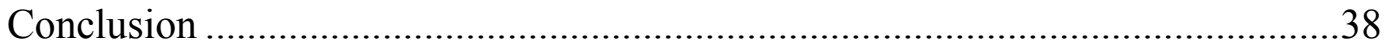

III. THE ARRIVAL OF TIBETAN BUDDHISM IN AMERICA.....................................41 Chögyam Trungpa Rinpoche and His Transformation of Tibetan Buddhism in the West

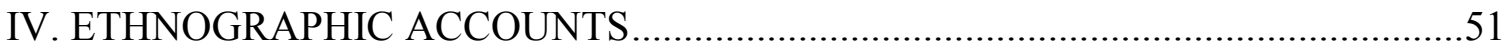

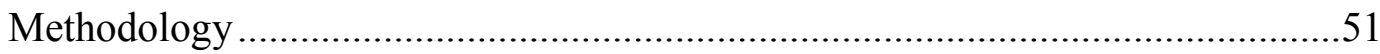

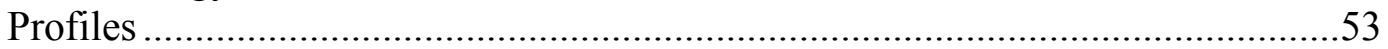

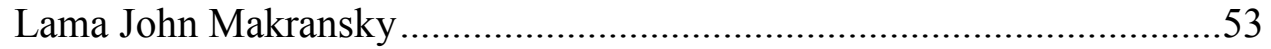

The Retreat Center …………………………………….............55

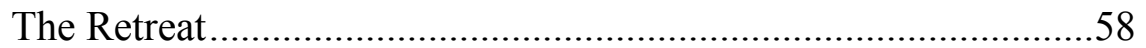

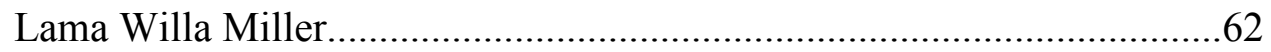

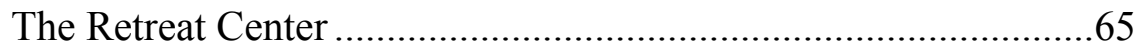

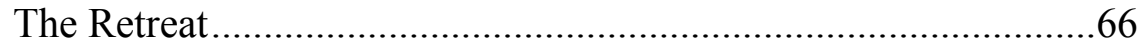

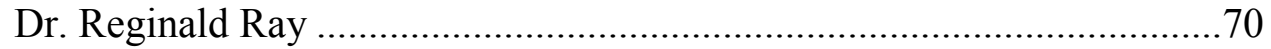

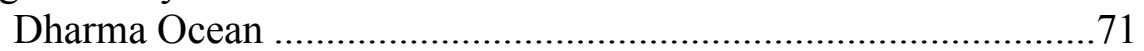

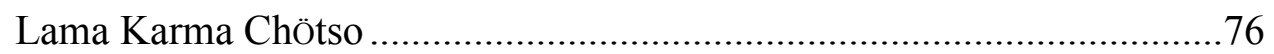

Kagyu Shedrup Chöling …………………………….................

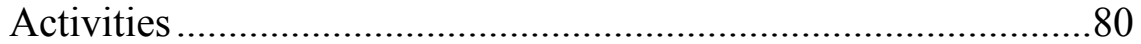

V. LOCATING THE LAMA WITHIN AMERICAN TIBETAN BUDDHISM ..............83

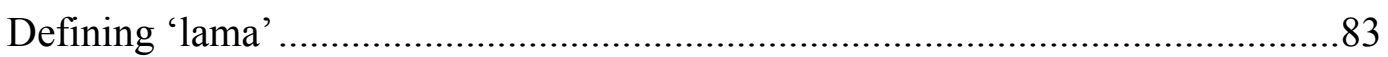

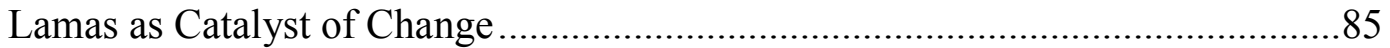

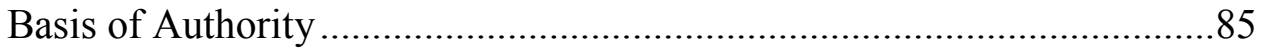

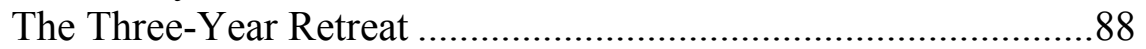




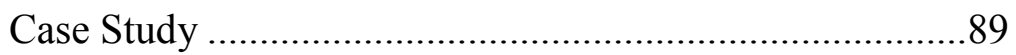

Preservation Versus Transformation......................................................92

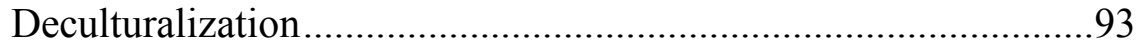

Incorporation of New Elements .............................................95

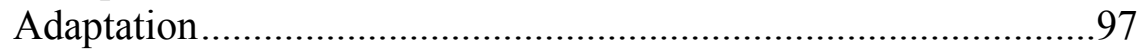

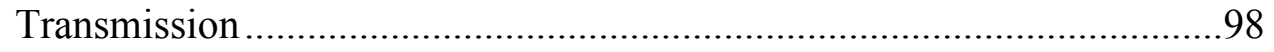

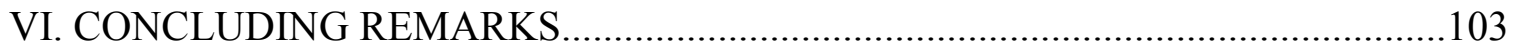

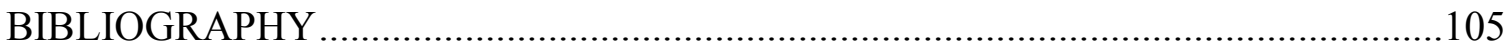




\section{LIST OF FIGURES}

FIGURE

PAGE

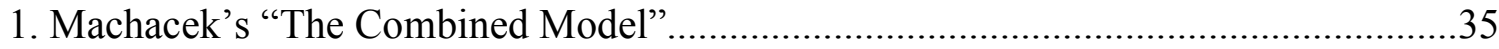

2. Dharma Hall at Barre Center for Buddhist Studies.....................................................57

3. Meditation Hall at Wonderwell Mountain Refuge..................................................66

4. Panoramic view of the Shrine room at Kagyu Shedrup Chöling..................................79

5. Stupa Garden of Merit at Kagyu Shedrup Chöling.............................. 80 


\section{CHAPTER I: INTRODUCTION}

"When the iron bird flies, and horses run on wheels, the Tibetan people will be scattered like ants across the world, and the Dharma will come to the land of the red faced people" - Attributed to Padmasambhava, $8^{\text {th }}$ Century (Surya 23).

In order to understand the changes and adaptations specific to Tibetan Buddhism in America, my thesis explored the ways in which western Buddhist lamas are trained and appointed, and the roles that they assume within the western form of Tibetan Buddhism. By analyzing how this practice has been modified and adapted from the Tibetan Buddhist tradition, distinctive characteristics of the western form of the tradition are identified and thereby establishing it as a unique Buddhist tradition in its own right. Throughout this study, the western from of the Tibetan Buddhist tradition will be referred to as 'American Tibetan Buddhism' (ATB) to reflect both its Tibetan sources and uniquely American style.

\section{Significance of Study}

Most of the current research in the field of American Buddhism focuses on the characteristics and background of Buddhist practitioners. However, in order to gain a broader perspective on the topic, there is a need for research and exploration of other areas pertinent to study of American Buddhism. One such area that has not been yet explored in depth is the study of leadership roles within Buddhism in America. My thesis seeks to address this gap in the literature by studying the role of the lama within Tibetan Buddhism in the west. 
When describing the process of change, it is essential to identify the agents of change within a certain group or tradition. Although practitioners are in fact a crucial aspect that has influenced the development of Tibetan Buddhism in America, leadership roles - such as the role of the lama - are influential positions that continuously shape the development and transformation of the tradition in the west. In order to understand how the tradition is transformed, we not only need to look at the practitioners, as has been the main focus of scholarship in the area of American Buddhist Studies, we also need to look at those who are imparting the teachings. In holding a position of authority, the lama acts as a catalyst of change within his/her group and in the overall process of change and adaptation of the Tibetan Buddhist tradition in America, towards what may become 'American Tibetan Buddhism.' While most of the scholarship has focused on studying different characteristics of the practitioner of Tibetan Buddhism in the west, the present study contributes to the understanding of the transformation of the tradition in the west by focusing on the teacher's role within the tradition. The exploration of ideas of selfperception by western lamas within the Tibetan Buddhist tradition allows for an understanding of their self-perceived roles, which in turn shape the teaching styles and practices of the lamas and consequently the passing down and transformation of the tradition in the west.

\section{American Buddhism}

In broader terms, the term "American Buddhism" can refer to the different cultural variations of Buddhism (e.g., Japanese Zen Buddhism, Theravada (South Asia) Buddhism, or Tibetan Buddhism), which have been transformed by their interactions 
with American culture; or to traditions that have developed their own particular characteristics based on traditional practices and the influence of western culture. In this sense, "American Buddhism" refers to these modified Buddhist traditions that are practiced in America.

The central issue, reflected in the way scholars have developed categories of classifying and distinguishing 'Buddhism in America' from 'American Buddhism,' depends on the specific figures in the development of 'American Buddhism.' On one hand, there are Asian Buddhist immigrants whose Buddhism has been clearly shaped by their arrival and settlement in America, and which has taken forms distinct from its original Asian roots. On the other hand, there is the Buddhism practiced by westerners, which has developed specific adaptations to fit its new audience, and has also diverged from its original Asian forms. This is then a central issue in the categorization of Buddhism in the west, and a determining aspect in the debate of what should be called 'American Buddhism.'

Since Charles S. Prebish first introduced the concept of "Two Buddhisms" in his book American Buddhism, many scholars have referenced the difficulties and challenges in categorizing Buddhism in America. Scholars, such as Prebish, Thomas Tweed, Richard Seager, Paul Numrich, Wakoh Shannon Hickey, and Jan Nattier, among others, have proposed different ways of categorizing Buddhism in the west on the basis of various criteria such as ethnicity, methods of transmission, and social organization. The problem of categorizing Buddhism in America, especially assigning the label "American Buddhism," has been an ongoing debate since this field of study was first pioneered by Prebish. After Helen Tworkvok's editorial in the Winter 1991 issue of Tricycle: The 
Buddhist Review, the heart of the debate centered on the differentiation between "Buddhism in America" and "American Buddhism." Fields seems to agree with this understanding of "American Buddhism," as he states, " The future of American Buddhism will depend on the practice and study of American Buddhists... Buddhism will become American Buddhism simply and naturally by being practiced by Americans" ("The Future" 26). However, this distinction is problematic, since as Kenneth K. Tanaka observed, “... Buddhism becomes truly American only when white Americans become seriously involved. The form called "American Buddhism" can be distinguished from "Buddhism in America" as practiced by Asian American Buddhists" (Tanaka, "Epilogue" 288).

The differentiation between "American Buddhism" and "Buddhism in America" widens gap between the two lines of development of Buddhism in America, identified in Prebish's "Two Buddhisms," namely "convert" Buddhism, practiced mostly by white Americans, and "ethnic" Buddhism, practiced by Asian immigrants (Prebish, American Buddhism 51). The Buddhism practiced by Asian Americans was perceived as being "highly 'fundamentalist' or 'dogmatic' or 'devotional' by its rivals," while the Buddhism practiced by Caucasians was "deemed 'intellectually arrogant' or 'purely enlightenment seeking" by their Asian counterparts (Prebish, "Two Buddhisms Reconsidered" 189). Prebish makes the observation that "ethnic" Buddhist groups apparently felt that "they represented the various 'true lineages' and authentic heritage of Buddhist teaching, while the newer form of emergent American Buddhism felt it had made innovations that were both necessary and important for Buddhism's successful move to the West" ("Two Buddhisms Reconsidered” 189). 


\section{The Mahavamsa}

The notion that Buddhism becomes truly American only when Americans (of non-Asian heritage) become seriously involved is supported by the precedent set in the Mahavamsa, (translated The Great Chronicle), a Pali text of historical nature that narrates the arrival and establishment of Buddhism in Sri Lanka. Historically, this is the first record of Buddhism moving into a new land, and this account provides a valuable perspective on the process of transmission and authentication of the Dharma across geographical and cultural borders. The Mahavamsa enumerates the series of events that take place in the propagation and establishment of Buddhism in a new land. After several tasks for the propagation of the Dhamma (Srk: Dharma) had been completed such as bringing the Bodhi Tree to the Island, constructing thupas (Srk: stupas) and establishing of monasteries and a monastic sangha, King Tissa asked Mahinda, the monk responsible for bringing the Dharma to Sri Lanka, whether Buddhism was yet established in the island. Previously, when the Mahamegha Park was offered to the sangha, Mahinda had declared that Buddhism had been founded in the Island (Mahavamsa XV 26). However, the king now seeks further confirmation, and wants to know whether the establishment of the sasana (Buddha's doctrine) has been successful.

But the king, who had heard the preaching, seated himself at the thera's feet and asked: 'Does the doctrine of the Conqueror stand, sir?' 'Not yet, O ruler of men, only, O lord of nations, when the boundaries are established here for the uposatha-ceremony and the other acts (of religion), according to the command of the Conqueror, shall the doctrine stand.' (Mahavamsa XV 180-181).

While both the Mahavamsa and the Dipavamsa agree on this reply, the Samantapasadika, Buddhaghosa's commentary on the Vinaya Pitaka, offers a slight variation of Mahinda's response to the king. According to this text, when the king asks 
Mahinda whether the sasana was established yet in the Island, Mahinda responds, "Great king, the sasana is established but it has not taken root." Mahinda goes on to explain:

When, Great King, a youth born in the Island of Tambapanni [Sri Lanka], of parents belonging to the Island of Tambapanni, enters the Order in the Island of Tambapanni, learns the Vinaya in the Island of Tambapanni itself and teaches it in the Island of Tambapanni, then indeed, will the roots of the Dispensation have descended. (Samantapasadika V 105)

It is important to note that while Mahinda's answer requires the recitation of the Vinaya (the monastic code of conduct) by a native of Sri Lanka who has been trained and ordained in Sri Lanka, the ordination of such person does not have to be performed by a Sri Lankan. Bhikkhu Maharittha possessed all the qualifications set forth by monk Mahinda; therefore he was selected to recite the Vinaya in order to fulfill Mahinda's requirements for the establishment of Buddhism in Sri Lanka (Samantapasaddika V 105). Maharittha was a Sri Lankan, trained in Sri Lanka and even ordained in Sri Lanaka, but Mahinda, who was not from Sri Lanka, ordained him (Mahavamsa XVI 10-11).

In addition to affirming the establishment of the Dharma, Mahinda's answer is twofold in that it affirms the establishment of the Dharma, but also declares the need for the further development of the establishment of the Dharma in the Island. Rahula observes that these two answers refer to two different ceremonies that took place at different times. The establishment of the boundaries of the sima was done accordingly, and the city was included in the sima at the desire of the king (Rahula 55). The ceremony for establishing the sasana, was performed at a much later time, after the Bodhi-tree was planted, marking a further development in the establishment of the Dharma (Rahula 56). As Rahula observes, although we are provided with two seemingly different answers, they both accomplish the same purpose: "A sima is necessary for Acts of the Sangha, 
where the recitation of the Vinaya is essential. The recital of the Vinaya (by MahaArittha) before the Sangha is tantamount to an act of the Sangha. Thus the establishment of the Sasana is ultimately reduced to the establishment of the Sangha which is not possible without a sima and the recital of the Vinaya" (Rahula 56).

The establishment of Buddhism seems to be directly linked to the establishment of a monastic order and the necessary elements for their success, such as the establishment of a monastery, the presence of the relics and the consequent building of a stupa, the establishment of the bhikkhuni order, the planting of the Bodhi-tree, and the recitation of the Vinaya. Furthermore, the recitation of the Vinaya can be seen as the event that confirms that all other requisites have been fulfilled. The establishment of an indigenous sangha or monastic order, upholding the monastic discipline and practicing the recitation of its precepts, is a requirement for the firm establishment of Buddhism in the Island.

Thus, this passage illustrates that in order for Buddhism to be considered to have taken root in Sri Lanka, Sri Lankans need to be able to be ordained and trained in Sri Lanka. The implication is that the creation of an indigenous sangha with the full involvement of the Sri Lankan people in all aspects of the practice of Buddhism is necessary for Buddhism to become Sri Lankan. In this context and under this interpretation, it could be said that for Buddhism to become American, the full involvement of Americans is necessary. 


\section{Tibetan Buddhism in America}

Tibetan Buddhism is among the major forms of Buddhism practiced in the United States by Americans. My thesis is concerned with the form of American Buddhism that is derived from the Tibetan Buddhist traditions, referred to as American Tibetan Buddhism (ATB). Even though this hybrid form of Buddhism is founded on traditional Tibetan principles, practices and symbols, some of its practices and rituals have been modified to adapt to its new cultural context. Buddhist "religious practices vary among the many branches and schools of Buddhism, and local expressions of Buddhism draw from the unique cultures of different areas," and this is no different in America (Numrich, "Buddhism" 3). The interaction of Tibetan Buddhism with American culture allows for "new religious understandings and practices that emerge from these encounters [and] are part of becoming American (Numrich, "Buddhism” x).

Tibetan Buddhism, as a result of Tibet's geographical isolation, "was virtually unknown outside of its Himalayan stronghold" until 1959 when the Chinese invasion of Tibet caused the forced exile of many Tibetans_-including high ranking Buddhist lamas-allowing for Tibetan Buddhism to be introduced to the rest of the world, especially the west (Cozort, “The Making” 221). Many of the exiled Tibetans, including prominent lamas, settled in India and Nepal: "Almost immediately, westerners began to find their ways to India and Nepal, to establish relationships with these teachers, and to invite them to travel and live in the West" (Cozort, "The Making" 221). The majority of Tibetan lamas arrived in America in the 1960-70's, a time in which "Tibet had come to represent the quintessential land of mystery and miracle" (Fields, How the Swans 282). Scholars such as Donald Lopez have criticized such idealization and romanticization of 
Tibet into the myth of Shangrila. In his book Prisoners of Shangrila. Lopez argues that the west has appropriated Tibetan culture and that Tibet and the Tibetan people have become objects of western fantasy. Nevertheless, this view of Tibet as an idyllic society, where Buddhism was present in its pristine form, provided a fertile environment where "ideological conditions [were] favorable to the welcoming of Buddhism" (Obadia, "Tibetan Buddhism" 4). Such a receptive attitude facilitated Tibetan Buddhism's "cultural translation and acceptance" and the development of specific adaptations to fit the western audience (Obadia, "Tibetan Buddhism" 4).

The receptivity of westerners to the Tibetan tradition, combined with the naiveté inherent in such wholehearted appropriation, provided a fertile field for Tibetan lamas such as Chögyam Trungpa Rinpoche to both critique the western materialistic worldview, as well as to make use of a historic opportunity to transform the tradition itself to speak to a western audience, giving rise to a form of Tibetan Buddhism which—while built on traditional concepts - has taken a form of its own in America. Chögyam Trungpa Rinpoche deliberately chose to freely transform his Tibetan Buddhist Tradition into a western form, unlike other lamas who preceded his arrival to America such as Geshe Wangyal, Deshong Rinpoche, and Tarthang Tulku, who promoted a traditionalist approach. The life and legacy of Chögyam Trungpa Rinpoche as one of the most important figures in the development of Tibetan Buddhism in America and its transformation into Tibetan American Buddhism will be discussed in further detail in Chapter 2. 
Unlike some other forms of Buddhism found in America, such as Theravada Buddhism, "the settlement of Tibetan Buddhism has no connection with the [Tibetan] diaspora" (Obadia, "Tibetan Buddhism" 6). Obadia's point may be overstated, but nevertheless it is revealing. In the United States, we find Theravada Buddhist centers, such as the Wat Buddharangsi of Miami, a Thai Theravada Buddhist Temple, which were specifically established to address the needs of the Asian immigrant Buddhist community. Like Wat Buddharangsi, many other Thai or Vietnamese Theravada temples across America were established for the purpose of fulfilling the needs of Asian immigrants, rather than to appeal to the western/American public. Reflected in the temple's organizational structure, the nature of activities performed at the temple, and the active presence of monks living in and running the temples: "The vast majority of these monks are Asian nationals, often possessing only minimal English-Language proficiency and a passing acquaintance with American culture, who have been imported from the home countries to staff the immigrant temples" (Numrich, "Theravada" 150).

It is in fact the case at Wat Buddharangsi; besides being run exclusively by Thai monks with limited knowledge of English, the activities the temple sponsors are almost exclusively directed to the Asian community. Some examples include the celebration of the Thai Mother's Day and the Thai New Year, as well as hosting a summer school where the Thai language is taught to children. The temple then operates as a supportive center for the lay Buddhists of the Asian immigrant community, serving not only "the spiritual but also the cultural and social needs of their members" (Tanaka, "Epilogue" 287). However, as a result of the temple becoming more established and their activities becoming better known in the area, westerners became interested in the temple's 
activities and Buddhism in general, in this particular case in the Theravada form. In the case of Wat Buddharangsi, this phenomenon is reflected in the temple's attempts to address westerners' interest in Buddhism by offering meditation classes, both in Spanish and English, which target the particular South Florida community. At Wat Buddharangs, we can observe that both the Asian immigrant community and the western practitioners meet in the same temple; however they meet at different times and participate in different activities. Nevertheless, because of the interaction between an already-established Asian community and the development of a Buddhist temple to fulfill their needs, an interest from the part of westerners developed, providing a clear example of how the practice of Theravada Buddhism by Americans developed through interaction with the Asian Diaspora in the United States.

However, what this study calls 'American Tibetan Buddhism' (ATB) did not develop out of interaction with Tibetan communities in America; on the contrary, Tibetan Buddhism was mostly developed by westerners for a western audience, nevertheless guided by prominent Tibetan lamas. "Although the transmission of Tibetan teachings was initiated by monks and masters, the spread of Buddhist themes and practices to a larger audience was undertaken by lay networks. In fact, Tibetan masters came to teach... at the invitation of those lay pioneers who had come into contact with them" (Obadia, "Tibetan Buddhism" 7). However there have been exceptions to this paradigm, such as Geshe Wangyal, a Gelugpa lama who "immigrated to the United States from India in 1955 in order to serve as a priest for the Kalmyk-Mongolian community" in New Jersey ("A Complete History"). In order to respond to the religious needs of Tibetans in the greater New York area, Geshe Wangyal established in 1958 the Lamaist Monastery of America, 
now known as the Tibetan Learning Center, the first Tibetan monastery in America ("A Complete History"). Geshe Wangyal also "sponsored many Tibetan monastic scholars to come to the US and assist with monastery activities by giving teachings and performing religious ceremonies" (“A Complete History"). Wangyal attracted many American students, such as Jeffrey Hopkins and Robert Thurman-perhaps the two foremost scholars of Tibetan Buddhism in the western world - as well as many other Americans who studied with the erudite Geshe and the Tibetan monks at the monastery.

\section{Scope of Study}

In the initial stages of Tibetan Buddhism in America, Tibetan lamas-by invitation of western practitioners - were the heads of the movements. However, in the course of the development of the tradition, westerners succeeded their teachers and became lamas themselves. The fact that ATB is still developing, allows us to have access to first and second generation western Buddhist lamas. First-generation western lamas, refer to those who "were trained and authorized by Asian teachers; the second generation was sponsored primarily by western teachers from the first generation" (Prebish, Baumann, Westward 277). My thesis explored the significance of the role of lamas within ATB and their involvement in the transformation of Tibetan Buddhism in the western context, done with the purpose of identifying the major characteristics that differentiate ATB from the traditional form of Tibetan Buddhism, making ATB a unique and a new form of Buddhism in its own right. The project addresses specific questions and areas pertinent to the process of induction, transmission, and of the succession of Buddhist lamas in the west. 
The thesis seeks to address the following questions; what are the main characteristics that describe and define what it means to be a western lama? What is the process through which one becomes a lama? What is the basis of the lama's authority? Does a western lama see his or herself, and his/her practice as non-traditional? By asking such questions, my thesis addresses the following themes: 1) the authority of the western lama; including the processes through which a westerner becomes a lama, methods of transmission involved in becoming a lama, and the role of the lama; 2) the transformations of the Tibetan Buddhist tradition through the adoption, adaptation, and use of Tibetan Buddhism by western lamas; and 3) the development of the tradition in the western context, done with the purpose of identifying whether there are unique characteristics that can be evidence for the development of a unique form of Tibetan Buddhism in America.

\section{Methodology}

My study focuses on a contemporary analysis of western lamas, relying mostly on ethnographic research methods, consisting of partially structured interviews and observation during meditation retreats and teaching sessions. Existing literature on the history of Buddhism in America was employed in order to place ATB within a historical and theoretical context within the ongoing field of American Buddhism. Four western lamas were interviewed: the interviews consisted of open-ended questions with the purpose of allowing the lamas to elaborate on themes that they found most important and relevant to their experiences as lamas. The interviews covered topics ranging from their background in Buddhism, the process by which they became a lama, related rituals, their 
role and responsibilities as a lama, and the passing down of their lineage and the development of the tradition in the western context. Methodology will be further discussed in Chapter 3.

\section{Structure of Study}

Chapter 1 provides an introduction to the main issues relevant to this study, including: the contribution of this study, a brief introduction to the study of Buddhism in America, the Mahavamsa text as the first historical record of the establishment of Buddhism in a new geographical area, a short introduction to the history of Tibetan Buddhism in America, the scope of this study and a brief introduction to the methodology employed in this thesis. Chapter 2 reviews existing literature on the study of Buddhism in America, which has mainly focused on the categorizations of Buddhism in America, emphasizing the need for research in other relevant areas in the study of Buddhism in America. Chapter 3 provides a history of the arrival of Tibetan Buddhism in America, focusing on Chögyam Trungpa Rinpoche, the fist Tibetan lama who actively sought to transform and adapt the tradition to the western context. Chapter 4 describes fieldwork, providing a profile of each of the lamas interviewed. Chapter 5 concludes the study by analyzing issues related to the authority of the lamas, including their source of authority, the use of such authority and the transmission of their lineage reflected in their teaching styles. 


\section{CHAPTER II: THE AMERICAN BUDDHIST LANDSCAPE: CATEGORIZING BUDDHISM IN AMERICA.}

\section{Two Buddhisms, Three Buddhisms, Too Many Buddhisms}

The categorization of Buddhism in America according to characteristics of the practitioners has been the main concern of scholars in the field American Buddhist Studies. As scholars have noted, Buddhist practices are diverse, especially in the United States where we find the different Buddhist traditions (e.g., Theravada, Mahayana, Vajrayana), as well as their cultural variations (e.g., Thai Theravada, Japanese Zen, Tibetan Buddhism) present at the same time in the same geographical area-a rather unprecedented phenomenon in the history of the development of Buddhism (Gregory, 252). "Tradition represented, country of origin, institutional form, social organization, practices, beliefs, soteriologies, and class and ethnic constituencies" are some of the variables that make up the variety of Buddhism found in America (Gregory 241). Some scholars have noted that it is necessary to speak of "Buddhisms" in plural, rather than "Buddhism" in singular, to account for the diversity in the variations of Buddhism present in America and the world (Yaryan 6; Gregory 240).

Different typologies have been proposed by scholars to categorize Buddhism in America in an effort to make sense of the myriad of beliefs, practices, and other variables encountered in the American Buddhist landscape. Scholars have approached the task of categorization from different perspectives, using different criteria to categorize the different types of Buddhism into groups. Some scholars separate Buddhism on the basis of ethnicity, differentiating between what they call "convert" Buddhist, comprised of 
mostly Caucasian, and "ethnic" Buddhist, mostly Asian immigrants (Prebish, Numrich, Fields, Tweed, Gregory). Other scholars define their typologies on mode of transmission (Nattier), while others categorize Buddhism on the basis of the style of practice (Layman, Tanaka, Freiberger). Lastly, some scholars have argued these categories to be limiting and one-dimensional, therefore opting for a multi-layered approach, where they often combine the two major models (categorization based on ethnicity and categorization based on modes of transmission), in order to paint a broader and more encompassing picture of the American Buddhist landscape (Machacek, Obadia). In general terms, in all these methods of categorization scholars have mainly focused on the identifying characteristics of the members or practitioners of particular Buddhist groups in the west, giving us insight on only one aspect of the teacher-student dynamic. Chapter 2 gives an overview of the different methods of categorization. However, as is the aim of my thesis to addresses the other side of the teacher-student dynamic, the present chapter also explores how the teacher's role is influential in the development and transformation of Tibetan Buddhism in the west.

There are three major identifiable trends in the different typologies used to categorize Buddhism in America can be recognized: (1) A "Two Buddhisms" dichotomy, which regardless of style of practice or other variables, is generally framed along broad ethnic terms; (2) A "Three (or more) Buddhisms" classification, a more inclusive typology which adds a third category to account for the shortcomings perceived in the "Two Buddhisms" dichotomy; and (3) A "Multi-layered" typology which is often a combination of the first two. 


\section{"Two Buddhisms"}

Prebish first coined the term "Two Buddhisms" in his book American Buddhism, which started a major trend in the study of Buddhism in America that has continued to be developed. When Prebish first used the term "Two Buddhisms," he did not mean that there are only two kinds of Buddhism present in America; rather, he was pointing out that Buddhism in America had developed along two distinct lines (Prebish, American Buddhism 51). Even though it was not as explicit at the time, Prebish's "Two Buddhisms" marked a clear differentiation of Buddhist groups along ethnic lines. Prebish described the first group as "slow to develop, conservative in nature, and remarkably stable in growth, activity and teaching" which he later on identified with the "Buddhism practiced by essentially Asian American communities" a designation which later became known as "ethnic" Buddhism (Prebish, American Buddhism 51); "Two Buddhisms Reconsidered 187). Prebish describes the second line of development as "groups that seem to emerge shortly after radical social movements (such as the Beat Generation or the Drug Culture)...Stressing less the basic doctrine and painstaking practice, they usually build their attraction the promise of something new, frequently centered on the personal charisma of a flamboyant leader" (Prebish, American Buddhism 51). What he described as the second line of development became known as "convert" Buddhism, made up of mainly Caucasians of European American ancestry (Buster, "Variety" 311). The use of the terms "convert" and "ethnic" in reference to the different types of Buddhisms makes the ethnic divisions of the dichotomy more explicit, distinguishing "between the Asian communities of practitioners who have brought Buddhism to the 
West via migration and diasporas, and the Western communities who have welcomed and adopted Buddhist ideas and practices" (Obadia 1).

Peter Gregory builds upon the "Two Buddhisms" typology on the basis ethnicity differentiating between two separate groups of immigrants, "the first wave of Chinese and Japanese immigrants who came to the United States during the second half of the nineteenth century and the first quarter of the twentieth... from the second much larger new wave of immigrants and refugees from all over Asia that have entered the United States in the last third of the past century as a result of the changes in immigration laws in 1965" (Gregory 243). Therefore, Gregory's typology distinguishes among the Buddhism practiced by 'Asian-Americans,' 'immigrants,' and 'American converts' (Gregory 242). Gregory's categories are primarily defined by the role of Buddhism in the life of the practitioner. Gregory argues "Asian American and immigrant Buddhists tend to be Buddhist for different reasons" making reference to the issue of continuity versus change (244). Gregory, like Prebish, Numrich and Fields, points out that the practice of Buddhism for Asian Americans and immigrants, represents social and cultural continuity, it "reaffirms their sense of traditional identity by locating them within a particular community defined by family, ethnicity, culture, and national origin" (Gregory 244). While the practice of Buddhism for American converts represents change and transformation, their "involvement with Buddhism often entails a break with the traditional values with which they have been raised, sometimes precipitating a radical shift in their identity" (Gregory 244). 
Victor Hori, a third-generation Japanese-Canadian, also utilizes a "two Buddhism" typology following an ethnic divide. Hori distinguishes between the "ethnic" Buddhism of Asian Americans, and what he refers to as "missionary Buddhism." Hori defines his typology on the different modes of transmission of Buddhism to America employed by the two different groups, acknowledging that each group approaches Buddhism from different perspectives. On the one hand, "missionary Buddhism," is the Buddhism brought to America by Asian Buddhist teachers, whose primary intention was to teach Buddhism to westerners, as is the case of Senzaki Nyogen and Sasaki Sokei-an, Philip Kapleau, Robert Aitken, Suzuki Shunryu, Sasaki Joshu, and Chögyam Trungpa (Hori 2). People who fall under this category are converts "and almost all assume without question that Buddhism must be Westernized" (Hori 2). On the other hand, "ethnic Buddhism" arrived in the United States along with Asian immigrants not "through lone missionaries but via ethnic and national groups" (e.g., the Japanese, Chinese, and Southeast Asians) (Hori 2). Unlike practitioners of "missionary Buddhism," "ethnic Buddhists are not concerned with converting Westerners," rather their concern lays in "preserving their own ethnic culture and identity" (Hori 2). Hori is very critical of the American interpretation of Buddhism. In his opinion, Americans, rather than westernizing Buddhism, are "Orientalizing Westernism." He argues that "Just as pouring a little sweet-and-sour sauce over Western food does not make it Chinese, so also flourishing Buddhist terminology over Western concepts of self, society, and consciousness does not make them "essentials of Buddhism" (2). 
Thomas Tweed also provides a "Two Buddhisms" typology, and whether he uses the term or not, as he recognizes two basic groups: "converts" and "cradle" Buddhists. By "converts" he identifies Buddhist followers "of European and African descent who chose the faith for themselves;" the practice of Buddhism is a conscious choice for those under this category (Tweed, "Who is a Buddhist?" 19). Those who he calls "cradle" Buddhists, Tweed describes as "Buddhists who were born into the tradition," including "oldline" Buddhists, descendants of Asian immigrants, as well as the children of converts, since they too are being born into the faith (Tweed, "Who is a Buddhist?" 19). Tweed's typology provides more flexibility than his predecessor's "Two Buddhisms" dichotomy, since his categories are not strictly based on an ethnic/racial component. Tweed's "cradle" Buddhist category accounts for both Asian immigrants and the children of converts, regardless of their ethnic identity. In the same manner, Tweed's "convert" category is inclusive of both American born practitioners and Asian immigrants who were not raised Buddhists, but who instead by choice identify themselves as Buddhists (Hickey 19).

Tweed not only describes two categories of what he refers to as "adherents" of Buddhism, namely "cradle Buddhist who inherited the faith, and converts who chose it," but also argues that a two Buddhism typology is not all-inclusive of the "criteria for defining Buddhist identity" (Tweed, "Who is a Buddhist?" 20). In an attempt to define who is a Buddhist, Tweed distinguishes between "adherents" and "sympathizers" of Buddhism. What he calls "adherents" are those practitioners who self-consciously identify themselves as Buddhists, distinguished from "sympathizers" or what he often refers to as "night-stand Buddhists," those "who have not offered full or formal 
allegiance to the tradition" (Tweed, "Who is a Buddhist?" 20). According to Tweed, 'sympathizers' are those who might practice Buddhism one way or another, but when asked will not identify themselves as Buddhists. For Tweed, 'sympathizers' are equally important as 'adherents' in the development of Buddhism in the west, whether 'convert' or 'cradle.'

Paul Numrich has been a supporter of the "Two Buddhisms" typology, arguing that it "captures an indisputable category break in the experiences, perspectives, and practices of contemporary Buddhist groups in the United States and other western societies" (Numrich, "Two Buddhisms Further" 69). While Prebish's "Two Buddhisms" was not explicitly divided among ethnic lines, Numrich's appropriation of Prebish's typology is. According to Numrich, "ethnic identities and racial dynamics" have been important factors in the development of Buddhism in America. Therefore, using a "Two Buddhisms" typology with ethnicity as a determining factor for categorization, provides a major advantage in recognizing the "real differences in the historical appropriation of Buddhist identity" (Numrich, "Two Buddhisms Further" 65). On one hand, we have the "ethnic" or "culture" Buddhists, for whom the practice of Buddhism represents continuity and affirmation of the cultural identity and heritage of Asian American immigrants. On the other, for "convert" Buddhists, the practice of Buddhism represents a break with tradition, since, for them "the key issue is identity change rather than continuity," and Buddhism offers a "transformative function providing an alternative religious identity for people dissatisfied or disaffected from their religious upbringing" (Numrich, How the Swans 195). Hence, Numrich emphasizes the sociological function of the "Two Buddhisms" typology, arguing that placing "the primary emphasis on the ethnic/racial 
composition of Buddhist America...obscures the real value of a "two Buddhisms" approach" (Numrich, How the Swans 195). However, Numrich suggests going beyond the ethnic distinction, arguing that, the primary emphasis should be on the "function Buddhism plays in the lives of Buddhists in each category" emphasizing the social function of the "Two Buddhism" typology (Numrich, How the Swans 195).

Scholars have criticized Numrich's approach, arguing that it is limited and does not account for the diversity of practices of Buddhism in America. According to Wakoh Shannon Hickey, Numrich has derived his typology from observations of immigrantoriented Theravada communities, and it does not apply to "multi-ethnic or multi-racial congregations, some of which have emerged since his study" (7). Hickey also points out that Numrich's "Two Buddhisms" model does not account for Asian immigrants "who become interested in Buddhism after they arrive in the U.S., and therefore could be considered converts" (7). However, Numrich describes this behavior not as conversion, but as a reversion or "revisioning" of their Buddhist heritage (Numrich, "Two Buddhisms Further" 69).

Even though many scholars have criticized the "Two Buddhisms" approach as limited and one-dimensional, we cannot ignore the apparent division among Buddhist groups in America along ethnic lines. It is an important and determining component of how different Buddhist groups operate and form their identities. Rather than discarding such an approach entirely, we must get past the most obvious characteristic of the "Two Buddhisms" dichotomy, namely the division defined by ethnicity, and see what further implications can be drawn from the dichotomy. Prebish's categories are not only relevant when talking about ethnicity, but they also highlight the role and representation of 
Buddhism for practitioners of these two different groups. In his "Two Buddhisms" dichotomy, Prebish's focus is on who is practicing Buddhism in America, or "a demandside perspective" (Machacek 67). That is to say, the division between ethnic Buddhists and convert Buddhists is based on who is practicing Buddhism and the reasons why they practice Buddhism. Scholars have observed that for the "ethnic" Buddhists, who are mostly Asian immigrants, "Buddhism represents continuity, with an inherited cultural tradition" (Machacek 67). On the other hand, for "convert" Buddhists, most of whom are white Americans, "the practice of Buddhism represents a break with tradition" (Machacek 67). Here, the motivations for practicing Buddhism are different in these two groups, and "consequently the two groups are likely to make very different demands upon the religion" (Machacek 67).

Helen Tworkov's editorial in the Winter 1991 publication of Tricycle: The Buddhist Review, marked a new and controversial era in the differentiation of "American Buddhism" from "Buddhism in America." Tworkov's editorial provided a reflection on the development of what she called "American Buddhism," making the following claim: "The spokespeople for Buddhism in America have been, almost exclusively, educated members of the white middle class. Meanwhile, even with varying statistics, AsianAmerican Buddhists number at least one million, but so far they have not figured prominently in the development of something called American Buddhism." Tworkov's claim—-thought it does not explicitly use the term—also suggests a "Two Buddhisms" dichotomy denoted by ethnicity/race. Furthermore, the implication of this claim, according to Kenneth $\mathrm{K}$. Tanaka, is that "Buddhism becomes truly American only when white Americans become seriously involved. This is then referred to as "American 
Buddhism' distinguished from simply 'Buddhism in America,' i.e., Buddhism as a foreign religion practiced by Asian American Buddhists" ("Issues of Ethnicity" 4). According to Jan Nattier, Tworkov's claim implies that when it comes to Buddhism in America, "mere transmission is not enough: the product must be repackaged to suit the domestic market" (Nattier, "Who is a Buddhist" 191). The process of the Americanization of Buddhism, meaning, "having shed its ethnic and cultural trappings," acculturation becomes a qualifying aspect and the basis of distinguishing between "Buddhism in America” and “American Buddhism” (Gregory 248).

These assertions, prompted strong responses from the American Asian Buddhist community, such as that of Ryo Imamura, a third-generation Japanese priest who objected to the implications of Tworkov's assumption that "restricted 'American Buddhism' to mean 'white American Buddhism"” (Prebish, "Two Buddhisms Reconsidered" 191). Equating "American Buddhism" with the Buddhism practiced by Caucasian Americans, and "Buddhism in America" with the Buddhism practiced by Asian immigrants, explicitly emphasized the ethnic/racial divide of the "Two Buddhisms" notion. Hickey also criticizes Tworkov's claim since it implies an "assumption that 'white Buddhism' is authentic American Buddhism, and that 'Asian Buddhism' is an essentially foreign thing that happens to reside on American soil," finding it problematic, since it indicates a "presumed authority to define what 'American Buddhism' is for everyone" (Hickey 10). As Rick Fields noted in his article "Confessions of a White Buddhist" published in Tricycle: The Buddhist Review, a publication aimed at convert Buddhists, "[I]n the ongoing discussion about the meaning of an emergent 
'American Buddhism,' it is mainly white Buddhists who are busy doing the defining. Nor is it surprising that they're defining it in their own image" (54-56).

According to Richard Seager, the phrase "American Buddhism" was used in two different ways with two different connotations. Fist, it was used to refer to the "expressions of the dharma that developed among converts" and was meant to "convey the idea that converts' innovations were giving rise to uniquely American forms of Buddhism that could claim normative status and be understood as the wave of the future" (Seager 235). While some were using the phrase "American Buddhism" in that sense, others started to use it to convey quite the opposite. Indeed, the term was used as a way to point out the wide range of diverse expressions of the Dharma in America, associated with converts as well as with immigrants, and to make the point that "none can be characterized as normative" (Seager 235). The nuance in the emphasis of the two uses of "American Buddhism" provides a key to the ongoing debate about "which group can legitimately claim to carry the standard for the dharma in the United States" (Seager 235).

Rick Fields also uses a typology that invokes the "Two Buddhisms" dichotomy, adapting the use of the term to the controversy of "American Buddhism" versus "Buddhism in America." Fields recognizes two distinct groups in the development of Buddhism in America divided along ethnic lines, "Asian-American Buddhists" and "White Buddhists." He also recognizes a growing gap between the two groups where "The Asian-American Buddhists are going one way, the white American Buddhists another," that denotes a perception of "not one but two American Buddhisms" (Fields, "Confessions" 56). Fields focuses on the concerns that members of each of the two 
different groups have; "On the one hand, an Asian ethnic community builds a temple to protect and preserve its values, as well as to minister to the spiritual needs of its members. On the other hand, a mostly white and middle-class group adopts and adapts a Buddhism taught by a charismatic, or at least a compelling missionary" (Fields, "Divided Dharma" 196). While one group is concerned with continuity, the other is concerned with change and transformation.

Since Prebish, and throughout the development of the field of American Buddhism, many scholars have employed a "Two Buddhisms" dichotomy, whether they explicitly or implicitly use the term to classify the different Buddhist groups found in America on the basis of the characteristics of the practitioners. The "Two Buddhisms" typology acknowledges a classification characterized by a divide based on ethnic terms, mainly differentiating between "ethnic Asians born into a Buddhist cultural heritage, and non-Asian converts to Buddhism" (Numrich, "Two Buddhisms Further Considered" 55). Scholars have used different terms to label these two groups such as 'cradle' Buddhists and 'convert' Buddhists (Tweed), 'culture' Buddhists and 'convert' Buddhists (Numrich), 'ethnic' and 'convert' (Prebish), 'Asian-American' and 'White' Buddhists. Regardless of the terms used to refer to these two groups, they are all underpinned by the main distinguishing characteristic between these two groups: ethnicity. While such an approach has been controversial, as in the case of Tworvok's editorial, we cannot ignore such a prominent factor in the development of Buddhism in America. 


\section{Three (or more) Buddhisms}

In his article "Two Buddhisms Reconsidered," Prebish extends his "Two Buddhisms" typology to include a third category of classification. Prebish suggested using the categories of classification of Asian Religions in America proposed by Peter W.

Williams in his book American Religions. Williams uses a threefold typology meant to describe the impact of Asian religions on America: “(1) 'ethnic religions,' or those practiced by Asian immigrants, and to an extent, by their descendants, (2) 'export religions,' or those popular among well-educated, generally intellectual Americans, and (3) 'new religions,' or those developing... as revolutionary outgrows of religions cited in the first two categories" (Prebish, "Two Buddhisms Reconsidered" 192-193). The threefold typology is still based on a division along ethnic lines, with an added third category that accounts for the shortcomings present in a "Two Buddhisms" dichotomy.

When discussing practitioner of Buddhism in America in her book Buddhism in America, Emma Layman distinguishes between "American versus Asian Buddhists" suggesting a "Two Buddhisms" typology. However, Layman proposes a threefold classification of the major styles of Buddhism present in the United States on the basis of the type of practice: " the 'evangelistic' style of Nichiren Shoshu; the 'meditational' style of Zen, Tantric Buddhism, Satipathana, and T'ien Tai; and the 'church' style Buddhism exemplified especially by the Buddhist Churches of America but also characteristic of Jodo-shu, Nichiren-shu, Buddha's Universal Church, and others” (Layman 252). Rather than bulding her classification on the characteristics of individual practitioners, Layman's typology follows the characteristics present in particular sects of Buddhism. 
Richard Seager also proposes a threefold typology for the classification of Buddhist groups in America. While arguing that "there is no Buddhist 'type' in America" as a consequence of the diverse ethnic and racial backgrounds, he nevertheless asserts that there are at least three broadly defined Buddhist groups in America; converts, immigrants, and old-line Buddhists. Converts, according to Seager, are those native-born Americans, usually of European American descent, but also including Asian, African, and Native Americans, who have embraced the teachings of the Buddha (Seager 9). "Converts" as a category, thus refers to Buddhist who were not raised and educated in Buddhist communities. The second group, "immigrants"-as the name indicates - is composed of "immigrant and refugee Buddhists from a range of Asian nations who are in the process of transplanting and adapting their received traditions to this country" (Seager 9).

Finally, the category "old-line Buddhists" refers to the group of "Asian Americas, primarily from Chinese and Japanese backgrounds, who have practiced Buddhism in this country for four or five generations" (Seager 10). Old-line Buddhist are differentiated from converts and immigrants in the sense that they have not "discovered" Buddhism recently, as converts have, and are not concerned community building efforts as the immigrant group is (Seager 10). Seager's categories are basically an extension of the "Two Buddhisms" typology, though it is not solely and strictly defined by ethnicity. Seager further classifies "ethnic" practitioners by dividing them into two groups, immigrant and old-line, in order to account for the difference in approach between these two communities, despite both being composed of people of Asian descent. Seager's 
'convert' category, also goes on to accommodate those practitioners who regardless of background, (whether European, Asian, or African descent), who did not grow up in a Buddhist context.

Kenneth Tanaka's fourfold typology utilizes the "Two Buddhisms" classification determined by ethnicity, while dividing each category in two according to different characteristics: (1) New Asian American Buddhists (those who have mostly arrived in the United States since the 1960s: Vietnamese, Thai, Korean, Cambodian, Myanmar, Laotian, and Sri Lankan); (2) Old-line Asian American Buddhists (those who were established before World War II: Chinese and Japanese); (3) Convert Buddhists whose main practice is meditation (predominately Euro-Americans practicing in the Zen, Vipassana, and Tibetan traditions); (4) Convert Buddhists whose main practice is chanting (Sokagakkai International-USA, a sizable percentage of whom are African and Hispanic Americans) (Tanaka 116). Tanaka's Asian-American category is divided according to the time of arrival of each group of Asian immigrants, accounting for the two main waves immigration from Asia. Those who came before the Asian Exclusion Act of 1924 that marked the first wave of Asian immigrants, fall under the "Old-line Asian American Buddhists" category, while "New Asian American Buddhists" refers to the larger wave of Asian immigrants coming to the United States after the changes in immigration laws in 1965. The "convert" category is also divided in two based on their type of practice, meditation, and chanting. These two groups also seem to be ethnically divided, those who practice meditation, according to Tanaka, tend to be predominately Caucasian Americans, while those who practice chanting tend to be more ethnically 
diverse including African American and Hispanic Americas. While Tanaka expands the number of categories, his classification remains divided along ethnicity.

Jan Nattier's threefold typology breaks away from the trend of categorizing Buddhism in America based on the practitioner's characteristics - whether ethnicity, approach, practices, etcetera - and categorizes Buddhist groups according to modes of transmission. Jan Nattier, nevertheless, does recognize the relevance of the "Two Buddhisms" approach, observing the obvious distinction between what she calls "hereditary Buddhists" or practitioners of Asian descent, and "converts" who were not born into the faith but who have become Buddhist by conversion (Nattier, "Buddhism" 74). While recognizing the obvious ethnic divide among Buddhist groups in America, Nattier argues that it is not quite as black-and-white as it appears, and seeks to expose the gray areas. For example, Nattier points out that while converts are predominately Caucasian, the convert group also includes African Americans, Latinos and even what she calls Asian-American "re-converts" (Nattier, "Buddhism" 74).

Rather than relying on ethnicity, Nattier proposes an entirely different way of categorizing Buddhist groups in America characterized by "the ways in which these various forms of American Buddhism were transmitted to the United States" (Nattier, "Buddhism" 75). Nattier's threefold typology distinguishes between three major modes of transmission: import, export and baggage. "Religions transmitted according to the 'import' model are, so to speak, demand driven: the consumer (i.e. the potential convert) actively seeks out the faith. 'Export' religions are disseminated through missionary 
activity, while 'baggage' religions are transmitted whenever individuals or family bring their beliefs along when they move to a new place" (Nattier, "Buddhism" 75).

Nattier refers to the 'import' category as "Elite Buddhism" because of the nature of the import process. In order to import a religion, "two crucial resources are required: money and leisure time" (Nattier, "Buddhism" 76). The importer, "seeks out the product and takes the initiative to bring it home," therefore members of the elite group tend to have a certain degree of economic privilege, and are usually members of the uppermiddle class of European-American descent (Nattier, "Buddhism" 76). Nattier makes the observation that the focus on the practice of mediation is the most striking feature of Elite Buddhists, but even more significant it is not only the "heavy emphasis on mediation but its scanting of other aspects of traditional Buddhism" such as monasticism (Nattier, "Buddhism" 77). According to Nattier, Elite Buddhism represents not only a transplantation, but a transformation of Buddhism which has "reshaped Buddhist ideas and practices in significant ways, yielding a genuinely new religious "product" uniquely adapted to certain segments of the American 'market"” (Nattier, "Buddhism" 77). Tibetan Buddhism in America is characteristic of the "elite" category as proposed by Nattier, rather than developing out of the interaction with an immigrant community, Tibetan Buddhism in America developed out of the interest of Americans themselves, who often traveled abroad to seek out the tradition and subsequently import it to the west. The ways in which a majority of the lamas interviewed for my thesis encountered Buddhism, exemplify the characteristics of members of Nattier's "elite" category. A detailed account of their encounter with Buddhism is provided in chapter 4. 
The "export" Buddhism category—also referred to as Evangelical Buddhism by Nattier-refers to the method of transmission where the religion is not "sought out by people residing in the United States, but which is brought here by citizens of other countries who come to these shores as missionaries" (Nattier, "Visible" 45). Export Buddhism is supply-driven, that is to say, the interest comes from the exporter and not the convert. Export Buddhism does not require money or time on the part of the convert, as does Elite Buddhism.

Finally, "Baggage" Buddhism, called "ethnic" Buddhism by Nattier, is the type of Buddhism that arrives to the United States through Asian immigrants. "Baggage" Buddhism differs from "export" Buddhism in its motivation: "while the founder of an Export Buddhist group comes to this country for purposes of propagation, members of the Baggage Buddhism category travel for reasons that have nothing to do with religion at all" (Nattier, "Visible" 47). Members of this group travel to the United States for personal reasons, such as economic opportunity, and just happen to bring Buddhism along with them. Nattier observes that members of this group tend to be monoethnic at the outset, since Buddhism for this group tends to be a "key element in self-preservation" and cultural identity (Nattier, "Visible" 47). For Nattier, it is these characteristics -the " divergent styles of transmission, not matters of doctrine, practice, or national origin, that have shaped the most crucial differences within American Buddhism" (Nattier, "Buddhism" 75). Nattier's categories allow for an exploration of other areas pertinent to the study of Buddhism in America apart from the ethnic component that has been the focus of other scholarship. By looking at the methods of transmission of a religion from 
one geographical area to another, we can explore issues such as the intention of the "importers," as is the case of the "elite Buddhism" category, allowing for an understanding of how the intentions of the importers shape the transformation of a tradition once it has been established in a new place.

Martin Baumann rejects both the "Two Buddhisms" notion and Nattier's classification defined by modes of transmission. According to Baumann, the "Two Buddhisms" binary differentiation holds true in some cases, but becomes meaningless rather quickly as Buddhism develops in the west. Bauman argues that the categories proposed by the "Two Buddhisms" dichotomy, immigrant and convert, only "differentiate and qualify the first generation of each strand. They become blurred and meaningless, however, when applied to consecutive generations and a longer span of time" (Baumann, "Global" 24). Baumann argues that the label "immigrant" does not apply to subsequent generations of Asian Immigrants. In a historical perspective "the category of immigrant is too transitory and in the long run a misnomer" (Bauman, "Global" 24). In the same way, the label "convert" does not adequately apply to the children of convert Buddhists, since they have not converted but rather were born into Buddhism. According to Baumann, "the categories of immigrant and convert are labels to differentiate and qualify the first generation of each strand. They become blurred and increasingly meaningless, however, when applied to consecutive generations and a longer span of time" and are therefore are not an adequate way to classify Buddhist groups in America over time (Bauman "Global” 24). 
Bauman also rejects Nattier's threefold categorization, arguing that "it is not primarily a question of transmission, that is, how a particular strand arrived in the West, but rather, which religious concepts and practices are favored" (Baumann, "Protective" 58). Baumann therefore proposes the categories 'traditionalists' and 'modernists' for the classification of Buddhism in the west (Baumann, "Protective" 58). Traditionalist Buddhism, according to Baumann, emphasizes "devotion, ritual, and specific cosmological concepts", while modernist Buddhism emphasizes "mediation, text reading, and rational understanding" (Baumann, "Protective" 58). While "traditionalists" strive to acquire merit in order to attain better conditions in the next life, holding a strong belief in rebirth, "modernists" "endeavor to reach 'enlightenment' or 'awakening' in this life" rather than acquiring merit for a next life (Baumann, "Protective" 58). A third category, "Post-modernist" Buddhism, refers to the practice of Buddhism and understanding its concepts in secular and psychological terms (Hickey 13). Although Baumann rejects the "Two Buddhisms" approach based on ethnic divide, the descriptions of his categories "make traditionalist Buddhism characteristic of Asian Buddhists and modernist Buddhism characteristic of non-Asian Buddhist" (Numrich, "Two Buddhisms" 64). While Baumann's typology seems to be divided along ethnic lines, the differentiating characteristic is not ethnicity or race, but classification is done based on the religious concepts and practices of the different groups.

\section{Multi-Layered Typologies}

David Machacek proposes a fourfold typology resulting from the combination of the "Two Buddhisms" approach and Nattier's typology defined by modes of 
transmission. Machacek argues that either one of these typologies on its own only tells half of the story, but combined, they offer a more comprehensive understanding of the religious landscape in America, offering "both a descriptive and predictive power" (Machacek 64). Machaceck acknowledges the relevance of the "Two Buddhisms" approach in identifying the central role of ethnicity in the understanding of Buddhism in America, but argues that this only represents a demand-side perspective. On the other hand, Nattier's categories defined by modes of transmission represent a supply-side. Therefore, Machaceck utilizes both typologies to offer "The Combined Model" accounting for both supply and demand influences resulting in four categories: Traditional, Ethnic, Convert, and Americanized (67). The chart below is an illustration of his model.

Figure 1. Machacek's "The Combined Model"

SUPPLY-SIDE

\begin{tabular}{l|c|c|}
\multicolumn{1}{c}{ Heritage } & \multicolumn{1}{c}{ Proselytization } \\
\cline { 2 - 3 } DEMAND-SIDE & 1 & 2 \\
Immigrant & Traditional Buddhism & Ethnic Buddhism \\
\cline { 2 - 3 } & 4 & 3 \\
American-borm & Americanized Buddhism & Convert Buddhism \\
\cline { 2 - 3 } & & \\
\cline { 2 - 3 } & &
\end{tabular}

Fig. 1 The Combined Model

Traditional Buddhism refers to the type of Buddhism practiced by Asian immigrants who seek to maintain their religious and cultural heritage. Members of the Traditional 
Budhdism group are most concerned with the "preservation and transmission of religious and ethnic culture," making this type of Buddhism the "most traditional in the sense of emphasizing continuity of belief and practice from the society of origin" (Machacek 98). Members of the Ethnic Buddhism group are also Asian immigrants, but unlike Traditional Buddhists, Ethnic Buddhists become Buddhist only after their immigration. For them, "ethnic identity rather than loyalty to a religious heritage becomes the motivating factor in participation," as Buddhism provides a familiar cultural environment (Machacek 69). Convert Buddhism is practiced by individuals who were not born and raised in the tradition, but for whom Buddhism represents a break with their own religious backgrounds. These three categories represent the "ethnic" and "convert" sides of the "Two Buddhisms" typology.

The fourth category, Americanized Buddhism, according to Machacek, represents the future of Buddhism in America. The Americanized Buddhism category represents the evolving characteristic of Buddhist groups as new generations Buddhists, both the children of converts and the children of immigrants that have become part of the American Buddhist landscape. According to Machacek, "If a Buddhist organization is to survive in America beyond the generation of its founders, it must respond to the demands of its American-born members, and this usually involves a process of Americanizationa process of adaptation whereby the religion increasingly comes to resemble other American religions" (71). The fourth category is therefore meant to illustrate the stage of adaptation in the process of Americanization of Buddhist groups in America, representing the groups that "have successfully adapted to the circumstances of religion in the American social environment and established their place among the American Religions" 
(Machacek 74). Machacek projects that eventually most forms of Buddhism in America will become Americanized, therefore his model illustrates the identifiable and predictable stages in the process (74). However, Machacek suggests that the category of "Americanized Buddhism" only represents an ideal state, "which is probably never reached" (74). Machacek's combined model of demand and supply side influences map the inevitable progress of Buddhist groups in America toward Americanization "in a process of accommodation to American society" (81).

Finally, Wakoh Shannon Hickey, calls for a multi-layered approach rather then static typologies in the classification of Buddhism in America. Hickey argues that such approach should be inclusive of the many characteristics that make up Buddhist identity such as tradition (Theravada, Mahayana, or Vajrayana), lineage, stage of development, religious identity of its members, degree of affiliation of its members, dynamics of race, gender, class and generation found in a group, and practices and sociological needs fulfilled by a certain group (Hickey 20). According to Hickey, a layered approach "provides a much richer picture than any taxonomy based on static characterizations" (20). Hickey proposes the following categories for the classification of Buddhist groups in America: established, offshoot, transplant and new movement. Established groups are those who have been present in the United States for several generations, such as some Chinese Buddhist groups (Hickey 16). An offshoot group "emerges from an established group, sometimes by schism, and sometimes by a more gentle process" (Hickey 16). A transplant group is an established group which moves to a new environment, for example the Soka Gakkai, Theravda temples and Japanese Soto-shu temples (Hickey 16). Finally a new movement is characterized by having been "developed by someone who is not 
ordained by an established group, but who develops and promotes a form of religion that may draw from elements of an established tradition," such as some Vipassana Groups (Hickey 17). Hickey argues that such categories are not a set of "static or reified characteristics" but on the contrary, are meant to "emphasize the process by which groups move into new environments, e.g., through missionary efforts, and how those develop and change" (Hickey 16).

All of the methods of categorization proposed by scholars have only focused on the identifying characteristics of practitioners belonging to any particular group, such as ethnicity, socioeconomic background and level of education. However, there is a need for research and exploration of other areas pertinent to study of American Buddhism. One such area that has not been yet explored in depth is the study of leadership roles within Buddhism in America. This project seeks to address this gap in the literature by studying the role of the lama within American Tibetan Buddhism.

\section{Conclusion}

The majority of the scholarship in the field of American Buddhist studies has mainly focused on the identifying characteristics of the practitioners of the different types of Buddhism in America. While some scholars have approached the classification of these groups based on methods of transmission, such as Nattier's categories, ethnicity has been the predominant characteristic on which the different categories proposed by scholars have been based. Overall, the scholarship has focused on who the practitioners of Buddhism in America are. However, once we have established who the practitioners are, we need to move on to other areas of study in the field. An important area in need of 
exploration is the transformation and adaptation of the Buddhist traditions in America. In order to understand how a tradition changes and adapts to a setting, not only there is a need to look at the members of a group who are receiving and practicing the teachings, it is necessary to study those who are imparting the teachings and instructions. Leadership roles, as is the role of the lama in Tibetan Buddhism, are positions of authority that are central to the development and transformation of the tradition in the west. It is through the lamas that the tradition is changed and adapted through their teaching styles and approach to practice. How the lamas see themselves and what they perceive their role to be within the tradition directly influences the transformation of the tradition in the west.

Existing scholarship has emphasized the need for the study of leadership roles as an important aspect of the development of the Buddhist tradition in America. According to Prebish, when looking to the future of the Buddhist tradition in America, leadership roles are influential positions that might determine the shape of American Buddhism (Luminous 244). Prebish argues that "the role of the American Buddhist teacher is pivotal for preserving the integrity and to enhance the mission of each Buddhist community" (Luminous 244). Prebish also points out the importance of the continuation of the Buddhist lineages as an important aspect of the development of Buddhism in the west, an aspect in which the role of the lama is central and extremely influential. Layman also argues that the "increasing role of the 'Western' leader", such as the lama in the case of Tibetan Buddhism, is an important aspect in the development of an American sangha. Both Prebish and Seager, mention the importance of a new generation of leaders to guide the Buddhist communities in America. Both identify the importance of the training of 
lamas in the practice of the different traditions and lineages as means for the continuation and adaptation of the tradition.

My thesis contributes to the existing scholarship by exploring issues regarding the leadership role of the lama within the Tibetan Buddhist tradition in the west. By identifying the source of authority of western lamas in the Tibetan tradition, their use of such authority as reflected in their teaching methods and practices, and the ways they pass down the tradition and teachings to their students, emphasizing the teacher's perceptions of their role in the transmission of the tradition in the west. 


\section{CHAPTER III: THE ARRIVAL OF TIBETAN BUDDHISM IN AMERICA}

While Buddhism arrived in the United States in 1800s with Chinese immigration, the history of Tibetan Buddhism in America starts in the 1950s and 1960s. In 1959, as a consequence of the Chinese invasion of Tibet, many Tibetans--including high-ranking lamas - were forced into exile. The forced exile from a country that had previously been completely isolated was seen as the point when Tibetan Buddhism was introduced to the rest of the world, and the exiled lamas became the messengers of the Dharma. Most of the exiled lamas settled in India and Nepal, where many westerners had their first encounter with Tibetan Buddhism and its teachers. Eventually, many of these western students returned to their countries and invited the lamas to come and teach in the west.

Geshe Wangyal, who settled in New Jersey in 1955, was the first lama of the Tibetan Buddhist tradition to settle in the United States. Initially, he did not have any students, until "three Harvard students - Christopher George, Jeffrey Hopkins and Robert Thurman-discovered Geshe Wangyal and began coming down from Cambridge" to Columbia University in New York, where he taught academic classes (Fields, "How the Swans" 291). Because of the nature of his teaching method, which focused on the academic study of Buddhism, "the legacy of Geshe Wangyal is mainly felt in the arena of training scholars of Tibetan Buddhism" (Lavine 101).

Deshung Rinpoche's impact is also seen in the academic field of Buddhist studies. He "arrived at the University of Washington in Seattle in 1961" where he worked closely with some of the west's foundational scholars of Tibetan Buddhism-such as Gene Smith, Edward Conze, Turrell Wylie, and Leon Hurvitz-teaching Tibetan and Buddhist philosophy and helping to compile an English-Tibetan dictionary (Lavine 102; Fields, 
How the Swans 289). It took him ten years after his arrival to start teaching the Dharma to western students (Lavine 102). The first two Tibetan Buddhist traditions to settle in American soil, the Gelugpa tradition represented by Geshe Wangyal, and the Sakyapa order, represented by Deshung Rinpoche, "are traditionally famous in Tibet and now in their current North American incarnations for their emphasis on academic approaches to the study of Buddhism," which is clearly reflected in their legacy in the United States (Lavine 102).

The other two Tibetan lineages, the Nyingmapa and Kagyupa orders, unlike their predecessors in America, "focused more attention on meditation and contemplation, with particular emphasis on tantric ritual practice" (Lavine 102). The Nyingma teachings were introduced to America by Tarthang Tulku, who settled in Berkeley, California, in 1969. There he founded the Tibetan Nyingma Meditation Center, based on a traditional approach: he "prepared his students to undertake the traditional tantric preliminary practices, which commence with one hundred thousand full-body prostrations" (Lavine 102). The center's journal, Crystal Mirror, emphasized the traditional approach of the centers teaching, and this is reflected in the following statement published by the journal: "no adaptation of the practices done in Tibet has been made. We believe that the success and longevity of the Teachings depend on their being presented in the purity of their original form" (Fields, How the Swans 308). According to the Nyingma Meditation Center, "rituals were observed on the same date they have been in Tibet, according to the Tibetan lunar calendar. All the chanting was in Tibetan-a practice that made it necessary for students to take at least introductory classes in the language" (Fields, How the Swans 308). 
The Nyingma tradition was especially suitable for American lay practitioners, given the structure of the tradition itself. The "typical Nyingma situation was a community of family groups centered around a lama who was often married himself"' (Fields, How the Swans 307). The non-monastic structure characteristic in the Nyingma tradition was particularly well received by American lay practitioners, who sought the rigorous practices of Buddhism, while at the same time "attempting to integrate their normal working lives, complete with familial obligations and occupational constraints," a particular aspect of the Nyingma tradition that allowed it to adapt to the American environment while still adhering to tradition (Lavine 102).

The Kagyupa order of Tibetan Buddhism was the last order to be introduced to American soil. The Kagyu order was established in America in 1970 with the arrival of Chögyam Trungpa Rinpoche. Distinct from his Tibetan colleagues, Trungpa sought to deliberately transform his tradition to fit the new American setting. Trungpa's approach "may represent the most comprehensive attempt to merge the religious worldview of American Vajrayana with all other aspects of American life" (Lavine 103). I chose to focus on Chögyam Trungpa's life and legacy as the principal model for the transformation of Tibetan Buddhism to fit the western audience. As a result of Trungpa's efforts, the 1970s can be seen as a turning point where the first transformation of the Tibetan Buddhist tradition into an American form takes place. 


\section{Chögyam Trungpa Rinpoche and His Transformation of Tibetan Buddhism in the}

West

Even though there were other Tibetan Buddhist lamas like Geshe Wangyal, Deshung Rinpoche, and Tarthang Tulku, who arrived to the United States before him, the transmission of Tibetan Buddhism to America flourished during the 1970s with the arrival of Chögyam Trungpa Rinpoche. Unlike many other eastern gurus and Buddhist teachers who introduced eastern thought and spirituality to the west using traditional methods and approaches, Chögyam Trungpa Rinpoche's use of unorthodox and nontraditional methods proved to be highly effective in the transmission of Dharma to the west in a way that was innovative and in accordance to the place and context of his time.

Chögyam Trungpa's methods in transmitting the Dharma to the west can be classified by three key approaches: the translation of Dharma concepts into a simple, secular language, the establishment of centers for the study of Dharma through the arts, and "crazy wisdom". Of the three, the first two proved to be extremely successful, with his translations, centers and foundations still relevant today. In 1974, Trungpa founded the Naropa Institute in Boulder, Colorado, the first Buddhist University in the United States, as well as the Nalanda Foundation, which promoted the study of Dharma through the visual arts (Prebish, "Trungpa" 880). In 1973, Trungpa established the Tibetan Buddhist movement Vajradhatu International, which later became known as Shambhala International, to "promote the practice of Vajrayana Buddhism in America and Europe"(Bell 57-58). The Shambhala Tradition was "a unique blend of Vajrayana traditionalism and American innovation" which sought to transform the Tibetan Buddhist 
tradition in a way that westerners could easily understand ("Buddhism in America; the Vajrayana" 127).)

Trungpa did not appeal to Tibetans in the west, but rather sought to transmit Buddhism entirely to the west and to Westerners. Trungpa had a great understanding of "how to cross those cultural, historical, and ideological barriers that make the transmission of any genuine spiritual tradition so difficult" ("Recalling" 10). He believed that in order to transmit Buddhism to the west, it should "give rise to a western Buddhism." Therefore, Trungpa "sacrificed his thrones, servants, and all the ceremony that traditionally surrounds a master. When he realized these aspects of his culture were meaningless in his new American context, he dropped them" (Midal 7).

Trungpa was among the very first Tibetan Buddhist lamas to present and publish Buddhist teachings in English to westerners. He understood and was able to adapt his teachings to the mind and the hearts of westerners, maintaining and emphasizing the core principles of the tradition, while keeping the essence of the teachings when adapting it to the current times. It had been difficult and almost impossible to adequately present to westerners certain difficult concepts such as "emptiness" and "nonduality," however, Trungpa was successful in "rendering ancient Tibetan Buddhism into ordinary English and modern Psychology" that westerners found his teachings appealing and relevant to their lives (Paine 81).

Even though Trungpa's movement was “associated with the 'hippie' counterculture," he managed to "disappoint" some spiritual seekers because "he hardly looked (or acted) the part of a guru" (Paine 86). Trungpa did not fit the mold of the guru of the minds of westerners; "he wore business suits, he eschewed health foods in favor of 
steaks, and he smoked and drank" (Paine 86). Trungpa's eccentric behavior was attributed to his style of teaching, considered to be the "crazy wisdom" aspect of the Tantric tradition, which "became the hallmark of his teaching in America" (Bell 59). This "crazy wisdom" method, used to shake people into a different state of mind, was characteristic of Trungpa. Midal defines "Crazy Wisdom" as

A form of wisdom that goes beyond all reference points, to such a degree that for ordinary people it sometimes appears insane. Such wisdom is unlimited and unconditioned, expressing itself according to the situation, without concern for convention or politeness (154)

Trungpa's behavior was so outrageous, that "people who met him ...either became his students or were outraged by him" (Paine 105). Trungpa sought to shock people out of their mental habits, "their circus of internal distractions," to stun them into silence, so that "they may discover a core of rightness and kindness and happiness that has been there all along" (Paine 107).

While some of his followers "appreciated his total dedication to his spiritual teachings and his simultaneous ability to enjoy life, manifested through his love of alcohol and women" others saw his actions as corrupt, and were scared away from his movement (Encyclopedia 1591). Some thought his lifestyle was at odds with his spiritual teachings and his "crazy wisdom" techniques were irreconcilable with spirituality. The main problem resulting from his "crazy wisdom" approach was clearly seen after his passing. The issue of succession proved to be a difficult one in Trungpa's movement, as its common for charismatic groups, where " realignments of authority after the death of a founder often create a testing time for the stability of charismatic groups" (Bell 57). Even though he came from a traditional lineage of incarnate tulkus, which dictate special 
guidelines of succession, Vajradhatu was created to be specifically suited to circumstances found in the west. Vajradhatu, being part of the Vajrayana Tibetan Buddhist tradition, did not particularly seek to maintain all the traditional aspects, but rather only the essence of the teachings as Trungpa deemed appropriate for a western audience. Instead of the traditional tulku lineage succession, Trungpa's charismatic movement sought the "handing down of spiritual authority through pupillary ...channels of succession," while simultaneously attempting to "retain close association" with its is origins in order to "authenticate its position within the wider Vajrayana Buddhist world by stressing its location within the 'ancient tradition' of which it claims to be a part" (Bell 57).

Trungpa had a close inner circle of disciples, among them, his star pupil, an American by the name of Tom Rich, whom he appointed in 1976 as his "Vajra Regent" and gave the name of Osel Tendzin (Bell 63). As the Vajra Regent, Osel Tendzin "was to administer the religious community" in the event of his master's death (Bell 63). The case of Osel Tendzin is an example of what Weber describes as one of the solutions to the succession of charismatic authority, which is done by the "designation on the part of the charismatically leader of his own successor" (Weber, On Charisma 55). Trungpa passed away in 1987, leaving Osel Tendzin as the head of the movement. However, the type of succession based charismatic authority is also dependent on the "recognition on the part of the followers" which in this case represented a major obstacle in the succession of Trungpa by his chosen Regent. Osel Tendzin's succession proved to be controversial from the onset. In December 1988, it was revealed that Osel Tendzin's was HIV positive, "furthermore, he had known about his condition for four years and had 
continued to practice unprotected sex with male members of the sangha and with some females," a situation led many of the movement's followers to "declare that they could not longer accept the leadership of the regent largely because of the deception over his seropositive status and its tragic consequences" (Bell 65).

Many of the followers called for the resignation of the regent because of the circumstances, hurting the movement by dramatically damaging the strength of "charismatic authority" and movement through the "moral shock which so many had felt upon learning of the regent's behavior" (Bell 66). According to Weber, "the source of the effectiveness of charisma lies in the faith of the ruled, their approval of the designated successor is indispensable," and for many of the members of Trungpa's movement, faith in the regent had been lost (Bell 67). Since the first attempt at the succession of charismatic authority failed, the second attempt was characteristic of what Weber describes as "designation of a successor by the charismatically qualified administrative staff and his recognition by the community" (On Charisma 55).

In an attempt to save the reputation and integrity of the movement, many of the members appealed to Tibetan lamas of the lineage in order to maintain ties with the tradition, while at the same time legitimizing the group's position within the larger tradition. In 1990, Dilgo Khyentse, a Tibetan lama, "advised the regent to go into "strict retreat," the regent "announced his acceptance of the lama's instructions and remained in retreat until his death the following August" (Bell 68). After Osel Tendzin's death, Trungpa's eldest son Osel Rangdrol assumed the responsibility as the leader of the movement, which lead to the establishment of a new system of authority, and an institutionalized system of Dharma through the Shamabhala Training, representing an 
example of what Weber calls the "routinization of charisma" as an effort to keep Trungpa's teachings and movement alive after his passing.

Trungpa's movement, as many other eastern movements that came to the west, faced controversy. His organization did not escape the conflict and problems faced by other spiritual organizations, such as the sex scandals, organizational defects, and abusive leadership, as described by Goldberg. Trungpa's personality, his abuse of alcohol and numerous sexual partners, along his "crazy wisdom" style of teaching created controversy. However, many of his disciples did not question his unpredictable and uncommon behavior, since in accordance with the guru-teacher relationship and devotion, it was all accepted as a teaching. However, after Trungpa's death, the regent as the new head of the movement sought to follow this example of "crazy wisdom," and his actions seemed to cross the line for some of the followers. They saw the actions and behavior of the regent as having created "a dangerous and false impression capable of leading the general public to view the Vajradhatu as a fanatical Buddhist church" (Bell 65). There was also the question of whether the regent's actions, and how they were perceived, would in retrospect cause people to view the sexual activities and behavior of Trungpa in a similar light. The controversy did not only delegitimize the authority of the regent, but it threatened to do the same to their charismatic guru.

Chögyam Trungpa was one of the most influential Tibetan teachers on American soil, and one of the first to introduce Americans to Vajrayana Buddhism ("Asian" 264). His brilliant yet controversial approach to the transmission of Dharma to the west by western means proved to be highly effective. According to Layman, the westernization of Buddhist practices means essentially three things: (I) adjusting mediation techniques to 
an American lifestyle; (2) providing more English-language material for American adherents; and (3) minimizing what she calls the "Oriental trappings" of Buddhism" (Seager 238). As we have seen, Trungpa successfully accomplished all three parameters as proposed by Layman, having successfully westernized Buddhism and its practices. Nevertheless, the life and legacy of Chögyam Trungpa exemplify the many challenges that religious traditions face upon their establishment in a new place. Challenges such as the adaptation and transformation of the tradition, issues of authority and authenticity, the relevance of the charismatic figure and the "routinization of charisma" after the passing of a leader, as well as issues of succession are exemplified by Chögyam Trungpa's story and in his transformation of Buddhism to fit the western context. 


\section{CHAPTER IV: ETHNOGRAPHIC ACCOUNTS}

\section{Methodology}

My thesis employed the use of ethnographic research methods as the means of obtaining the material and information, including the use of interviews and observation during meditation retreats and teaching sessions. The case study made use of partially structured in-person interviews of four western, i.e., non-Asian lamas, belonging to the Tibetan Buddhist tradition in America. Selection for participation in the study was determined by the availability and willingness of the lamas to participate. The lamas selected represent different approaches and styles of teaching, both traditional to nontraditional, reflecting varying attitudes to the teaching and practice of Tibetan Buddhism in the west. The lamas interviewed were Lama Karma Chötso, in Miami, Florida; Lama John Makransky, in Barre, Massachusetts; Lama Willa Miller, in Springfield, New Hampshire; and Dr. Reginald Ray, in Boulder, Colorado. The interviews consisted of open-ended questions with the purpose of allowing the lamas to elaborate on themes that they found most important and relevant to their experiences as lamas and to explore their constructed ideas of self-perception. The interviews covered topics ranging from their background in Buddhism, the process by which they became a lama, related rituals, their role and responsibilities as a lama, and the passing down of their lineage and the development of the tradition in the western context.

Besides conducting interviews, participant-observation was employed by attending meditation retreats taught by the lamas being interviewed. On September 28 to September 30, 2012, I attended a 3-day weekend mediation retreat lead by Lama John Makransky, entitled "Knowing Persons in Their Deepest Goodness," offered at the Barre 
Center for Buddhist Studies in Barre, Massachusetts. I also attended a 3-day weekend retreat, on October 12 to October 15, 2012, lead by Lama Willa Miller, entitled "Mindfulness in the Mountains," offered at her own center, Wonderwell Mountain Refuge, in Springfield New Hampshire. As a result of time constraints and scheduling issues I was not able to attend one of Ray's retreats. Not being able to attend the retreat, as per Ray's suggestion and prior to his interview, I completed his recorded program called "Your Breathing Body," Vol. 1 and Vol. 2. I also attended a one-day mediation intensive retreat offered by Lama Karma Chötso on October 25, 2012 at her center Kagyu Shedrup Chöling, in El Portal, Florida. Over a period of 5 months, I also attended the weekly mediation classes offered for beginners, as well as other dharma related events held at Lama Karma Chötso's center. I also participated in events related to the Stupa Project, such as Spirit Miami and the weeklong events that lead to the final consecration of the stupas at Kagyu Shedrup Chöling. Participant-observation was employed during these retreats in order to evaluate their teaching methods, particularly the type of language used during teachings, and whether they choose to use Buddhist terms in Tibetan and/or Sanskrit, or more colloquial language and psychological terms.

The present section is concerned the ways in which the lamas interviewed perceive themselves and their roles within the Tibetan Buddhist tradition in the west. The present analysis is focused on the lama's self-published materials-including their personal as well as their organization's websites - audio recordings, observations during meditation/teaching retreats offered by the lamas, followed by personal interviews conducted after the retreats concluded. 


\section{Profiles}

\section{Lama John Makransky}

Retreat: "Knowing Persons in their Deepest Goodness"

September 28-30, 2012

Barre Center for Buddhist Studies

149 Lockwood Road, Barre, Massachusetts 01005

Lama John Makransky grew up in what he describes as a "very secularized and not religious" Jewish family. He attended Quaker schools, from nursery school all through high school, where besides receiving a secular education, he was trained in Quaker-style contemplative practices such as silent worship. Looking back, he recognizes these practices and some of his teachers as being formative in his spiritual development. It was not until he went to college that he really encountered Buddhism. He began taking Asian religion and philosophy courses, and upon finding Buddhism, he knew he had found what he had been looking for. Eventually, in 1975 he traveled to Nepal, where he felt like he was finally at home. Once in Kathmandu, he first encountered the Gelugpa lineage of Tibetan Buddhism, connecting with Kopan Monastery where he met Lama Yeshe and Lama Zopa. He became their student and spent several months practicing Buddhism and doing retreats. Before he traveled back to America, he lived for six months in Northern India where he also connected with the Dalai Lama.

Upon his return to the United States he encountered other prominent Tibetan lamas that had begun to teach westerners. He enrolled in a PhD program at the University of Wisconsin, where he studied under Venerable Geshe Sopa, a professor there, and was able to deepen in Buddhist studies while at the same time learning Tibetan and Sanskrit within an academic setting. Eventually, through his $\mathrm{PhD}$ research he began to study the 
other Tibetan lineages: first the Sakya, then the Kagyu, and eventually Nyingma. Then, through Lama Surya Das, a prominent western lama, he met Nyoshul Khen Rinpoche, a Tibetan Nyingma lama, whom he identifies as his deepest root teacher. Becoming completely involved in the Nyingma practice and tradition under the guidance of Nyoshul Khen Rinpoche and alongside Lama Surya Das, Makransky did extensive retreat practice. However, he never completed the traditional three year retreat, since his living situation as a professor at Boston College and familial obligations did not permit it.

As his practice deepened, Lama Surya Das began to ask him to respond to students' questions, to help at retreats, and to conduct interviews with students, eventually asking him to guide practice sessions and retreats and to informally assist in teachings. He had no intention to become a lama, but one day after one of the long summer retreats, Lama Surya Das made unannounced plans and installed him as a lama.

Lama Makransky's encounter with Buddhism is characteristic of what Jan Nattier calls "Import Buddhism" or "Elite Buddhism." As she has noted, this type of Buddhism is demand driven, and is characterized by the interest being sought out by the recipient, who typically travels to Asia and then brings the tradition back home with them (Nattier, "Visible" 43). As she notes, money and leisure time are necessary resources, and so members of this type of Buddhism usually belong to the well-educated upper and middle classes of society (Nattier, "Visible" 43). 


\section{The Retreat Center}

Lama John Makransky does not have a center of his own, rather, he teaches at different places where he is regularly invited. He teaches at other lamas' centers, such as Lama Willa's Wonderwell Mountain Refuge, Chokyi Nyima Rinpoche's Rangjung Yeshe Gomde in California, as well as at the Rangjung Yeshe Institute in Nepal, to name a few. Lama Makransky teaches at the Barre Center for Buddhist Studies typically twice a year, where he usually gives a weeklong retreat in the summer and weekend retreat in the fall.

According to their website, the Barre Center for Buddhist Studies is a "non-profit educational organization dedicated to exploring Buddhist thought and practice as a living tradition, faithful to its origins, yet adaptable to the current world. The center provides a bridge between study and practice, between scholarly understanding and meditative insight" (Barre Center For Buddhist Studies). Besides offering meditation retreats and programs, the center also offers academic classes, where guests such as Lama Makranasky might teach. As both as lama and a university professor of Buddhist studies, Lama Makransky is uniquely qualified to blend these two aspects of the vision of the Barre Center.

The center itself is located in a wooded and secluded rural area, only half a mile from the Insight Meditation Society, the oldest and most respected meditation retreat center in the west, which focuses on a form of Buddhist meditation known as Vipassana. The Barre Center for Buddhist Studies consists of a farmhouse, a Dharma hall found in a separate building, and three separate cottages. The farmhouse is an old, spacious threestory building where the offices, library, kitchen, dining room, a classroom and some 
accommodations for visitors are found. While some, but not many, Buddhist decorations can be seen, no one single tradition is represented; rather statues and paintings from the differing Buddhist traditions can be found throughout the building. A traditional Tibetan thangka, or painting of Vairocana Buddha, a thangka of the Bhavacakra, a glass sculpture of Kuan Yin, a Japanese scroll, a golden statue of Amitabh Buddha, a statue of the Wheel of Dharma, a bell and dorje, and many statues of what can be recognized as a "generic" Buddha are some examples. In this same manner, the library reflects the variety of Buddhist traditions that are studied and practiced at the center; one can find books from the Theravada tradition, as well as books on Zen, Chinese Buddhism, Tibetan Buddhism and other Buddhist traditions. As it is expressed in their website, their "programming is rooted in the classical Buddhist tradition of the earliest teachings and practices, but calls for dialogue with other schools of Buddhism and with other academic fields" (Barre Center for Buddhist Studies).

As you walk out of the farmhouse, heading towards the Dharma Hall, a big brass bell used to announce times for meditation and other activities hangs from a big tree in front. To the left side, in an open area, there is a small stupa-like structure made out of stone, encasing a Buddha statue. The Dharma Hall itself is a big spacious two-level building; accommodations for students are found on the ground floor, while the second level of the building is the main area where the mediation hall is found. Just before the actual mediation hall, there is a tea station and a reading hall where people gather during breaks.

The Dharma Hall is very simple and minimalistic; some would describe it as Zen like. There were no decorations or any Buddhist religious artifacts, except a single 
Buddha statue at the end of the room, and next to it a large singing bowl. In front of the statue, a place was set up for the teacher/lama that consisted of a raised platform with a mediation cushion, a microphone and a singing bowl. Meditation cushions of different styles, meditation benches and regular chairs were arranged to face towards the Buddha statue, and the teacher's seat. The meditation hall had no shrine, paintings, decorations, offerings, candles, incense, or any of the characteristic elements usually associated and found at traditional Buddhist temples or meditation halls, be it Theravada, Thai, Tibetan, Chinese or any other. Again, it was very simple and minimalistic, where no one single tradition was represented — the single Buddha statue was a "generic" representation of the Buddha that any one Buddhist tradition would recognize.

Fig. 2 Dharma Hall at Barre Center for Buddhist Studies

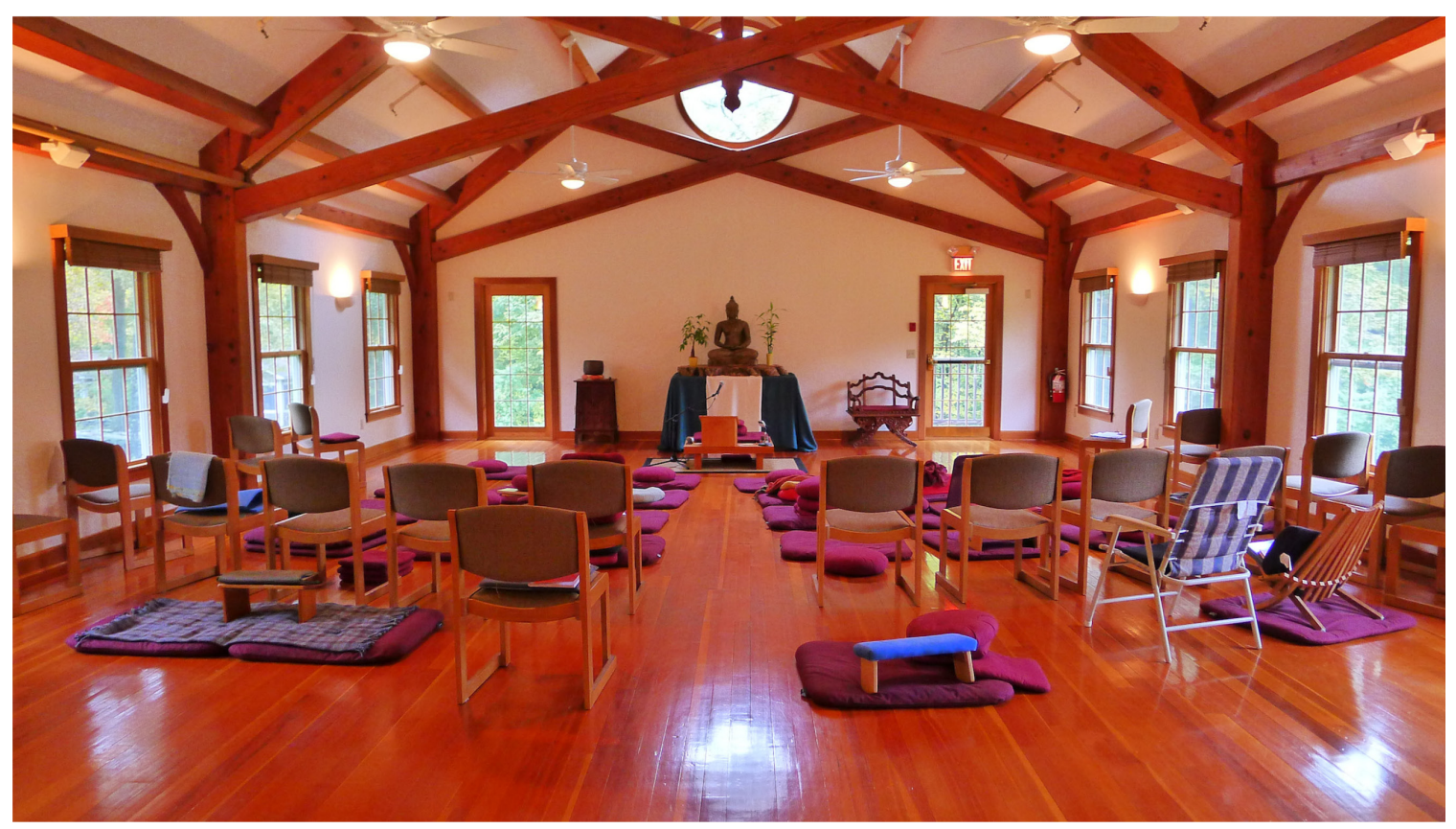




\section{The Retreat}

Thirty people attended the retreat, all Caucasian westerners of non-Asian heritage, between the ages of 50-70+, with the exception of a young man in his late 20's. The participants were professionals such as teachers and college professors, with high levels of education, most having completed a university education. The majority of participants in the retreat were females, 22 females and only 7 males. Since scholarship has focused mostly on ethnicity, socioeconomic status, and age, gender demographics have not been given the same attention within the typologies of categorization provided by scholars. Overall, the group of participants at this particular retreat was characteristic of what Jan Nattier calls "Elite" Buddhism, given their ethnicity, age, level of education and socioeconomic backgrounds. As it has been noted before, money and leisure time are necessary for members of such Buddhist groups, since the activities necessary for participation in this type of Buddhism requires time off to go into retreat, even if only for a weekend, and money to cover the expenses associated with it (Nattier, "Visible" 43).

One of the main obstacles of conducting fieldwork within this retreat setting was the nature of the retreat itself, as it was a silent retreat. Consequently, I was not able to establish relationships with participants, have conversations with them, or obtain voluntary information through unsolicited or solicited oral accounts.

The retreat I attended was titled "Knowing Persons in their Deepest Goodness," as it is described in The Foundation for Active Compassion Website:

This weekend retreat is for both new and experienced meditators. Practices from Tibetan tradition are adapted for fresh access to Westerners, with special focus on a Dzogchen approach to bodhichitta, the essence of loving compassion and wisdom that has been partly concealed within our minds. To receive love deeply and extend it impartially can help the mind release into its most natural state - the 
wisdom of openness, clarity and responsiveness beyond self-clinging. By resting in its natural state, the mind can further unleash its innate capacity of love. When this unity of love and wisdom is embodied in relationships, service and action, it becomes a force of deep healing. The ancient bodhisattva path of awakening is rediscovered as we pay new attention to the particulars of our entire lives. (Foundation for Active Compassion)

This description of the retreat is telling of Lama Makransky's teaching style and approach. He delivers traditional Tibetan Buddhist teachings and practices in a way that is "adapted for fresh access to Westerners" (Foundation for Active Compassion). He is most concerned, as he describes it, with providing access "...to some of the principles that I think are so profound within Tibetan Buddhism. Especially principles concerning the possibility of human awakening to our deep potential of compassion and wisdom..." (Makransky). Lama Makransky is oriented to a "multi-faith context," as he puts it, “...many Buddhists of different kinds show up in settings where I teach. But I'm also quite conscious that there are people formed in the Christian tradition, Jewish and other traditions, and I am speaking to them as well..." (Makransky). His approach is to provide a "...door of access to the Tibetan Buddhist tradition itself..." by speaking to his audience in their own context while keeping Tibetan Buddhist tradition at heart (Makransky). While his method and style of teaching might be characterized as westernized, adapted to the western audience and context, the heart of his teachings remains traditional. As he described it to me:

I do not consider what I'm doing something different from Tibetan Buddhism called American Buddhism, I do not think of it that way. And yet as you saw during the course of the retreat, obviously what I'm doing is not the same thing that a Tibetan lama would be doing with Tibetans, in terms of commenting upon and guiding, explaining the theory, guiding the practice, in a traditional form. Precisely in the traditional form with the traditional iconography and imagery and repeating in a way the standard explanation for much of what is being done in a form that Tibetans are 
familiar with, comfortable with, fits them in many ways. So then obviously I'm not doing that, and if I did do that, it would be as if I was teaching for some other group, other than the group that is here.

The delivery might be different, but the content remains unchanged. This was reflected throughout the retreat. Buddhist terms, the use of Sanskrit or Tibetan, were rarely used throughout the weekend retreat. Only one mantra, the Buddha Sakyamuni mantra " tayata om muni muni maha muniye soha" was repeatedly chanted before and after practices. Most people were familiar with this mantra, though, not everyone was.

Lama Makransky does not use a Tibetan name, but choses to use his western name, since in the type of settings he teaches, "it is hard for people to relate to a Tibetan name, it is not meaningful to them" (Makransky). Lama Makransky does not wear robes or any distinctive clothing that would set him apart from the other participants or identify him as a lama. However, people did demonstrate reverence towards him; upon him entering the room most people would stand up, place their hands in the prayer position and bow as he walked passed them, and people would then wait for him to sit down before they did so themselves.

Practices consisted of breathing exercises, guided meditation and visualization practices. The sound of a singing bowl would indicate the beginning and end of each practice. While these practices were traditional, as it has been previously noted, the delivery was adapted to the western context. An example is the practice of what Lama Makransky calls "spiritual benefactors," which was a central practice during this retreat. We were given a handout explaining the practice, which described it as a practice "adapted from Tibetan Buddhist meditation traditions for people of all backgrounds and faiths to explore." In this practice, we were asked to recall individuals that we identified 
as benefactors, someone "with whom you have felt happy, safe, well, loved." The examples given were Buddha, Bodhisattvas, the Dalai Lama, but also Jesus, Martin Luther King and Mother Theresa. Furthermore, if we were having difficulty with these types of figures, we could also recall even our pets as benefactors. This is an example of how Lama Makransky adapts the practice in a way that was accessible to westerners, for whom images of Buddhas and Bodhisattvas might be too abstract and not meaningful, while more culturally familiar figures such as Jesus and even their own pets, might be more relatable to their own cultural and personal situations.

While the practices might have been adapted and expressed in western terms, Lama Makransky places himself within the Tibetan tradition by continuously making reference to his Tibetan teachers and their texts, as well as foundational Buddhist teachings, such as the Four Noble Truths, The Five Skandhas or Aggregates, impermanence, ignorance, and Bodhicitta. As he phrases it, he provides

....another door of access to the Tibetan Buddhist tradition itself. So by connecting to me, if someone feels like they have begun to open to capacities of compassion and wisdom, through the practices that I teach and transmit, then I want them to understand that they have connected to the heart of Tibetan Buddhism itself.

In other words, he provides access to the Tibetan tradition in a way that is accessible and relatable to westerners and the tern context. 


\section{Lama Willa Miller}

Retreat: "Mindfulness in the Mountains"

Oct 12-15, 2012

Wonderwell Mountain Refuge

Springfield, New Hampshire

Lama Willa Miller was born in Portland, Oregon, and grew up in Berkeley, California. She was exposed to the Dharma from an early age. She describes her parents and the religious environment she grew up in as "atheist Buddhist." Her parents leaned towards Zen and Tibetan Buddhism, although they were not 'formally' Buddhists; “...they hadn't taken refuge, they hadn't done the sort of traditional things associated with Buddhist practice. But my father sat zazen,...My mother went to Buddhist teachings..." (Miller). When Lama Willa was 8 years old, her mother took her to a meditation practice at the Nyingma center in Berkeley founded by Thartang Tulku, one of the first Tibetan Lamas to teach in America. She also went on to learn Transcendental Meditation, and practiced it from grammar school through high school. While she had been exposed to Buddhism from early on, it was not until junior high school that she was really introduced to Buddhist teachings such as the Four Noble Truths. As she familiarized herself through reading books, her interest in Buddhism grew, especially in the Zen and Tibetan traditions.

Eventually she travelled to Nepal, where she spent a year living among Tibetan refugees as part of a study abroad program with the University of Wisconsin. Living among Tibetans, she experienced Tibetan Buddhism and its practices. Even though she was familiar with Buddhism and meditation, she was not really familiar with Tibetan Buddhist practice. She recalls one of her first experiences with this kind of practice: 
...There was this one old woman, she would go to the temple very close to my house. I could see her out of my window of my little hut. There was a temple that she would unlock at five in the morning and she would do prostrations every morning, and she would lock it again and go away. So one day she unlocked it and she started doing prostrations, so I went up and I stood behind her and I started imitating her, and I started doing what she was doing...

Her yearning for practice increased, but not knowing how to practice, she went to a local monastery and approached the rinpoche. As she felt very drawn to White Tara, a popular deity in Tibetan Buddhism, she asked the rinpoche for guidance on the practice associated with that deity. The rinpoche gave her the wang, or the empowerment or initiation into the practice of White Tara, and the lung, or the reading of the text of the practice, as well as the sadhana text for her to practice on her own.

Upon her return to the United States, Lama Willa met Kalu Rinpoche and Dilgo Khyentse Rinpoche, both prominent Tibetan Lamas in the west. It was then, during her senior year in college that she took refuge, the ritual through which one becomes formally Buddhist. She first took refuge with Dilgo Khyentse Rinpoche, and then with Kalu Rinpoche, both of whom would become her root lamas. During that same year, due to her yearning for Dharma and its practice, Lama Willa moved into Kagyu Thubten Chöling Monastery (KTC), a Kagyu monastery in New York founded by Lama Norlha Rinpoche in the tradition of Kalu Rinpoche. After living at the monastery for about three months, Lama Willa heard about the three year retreat, and even witnessed a group of women, among them Lama Karma Chötso, going into retreat. This was very inspiring to her, and her interest in the three year retreat increased to the point that she aspired to complete one herself. Since the men and women had just gone into retreat, she had to wait three years until the next retreat would start. During this time, Lama Willa graduated 
from college and continued to live at the monastery. After one and half years of living at the monastery as a layperson, Lama Willa was strongly encouraged by Lama Norlha Rinpoche to take ordination vows as a nun. When the opportunity arose, she went to India to take ordination with Kalu Rinpoche, which from a Tibetan perspective was a very auspicious occasion. On January 10, 1988, at the age of 23, Lama Willa along with other five people from KTC and another five westerners from Europe and other places around the world took ordination vows with Kalu Rinpoche in Bodhgaya, the place where the Buddha was enlightened. For the next two years, as she waited to go into the three year retreat, Lama Willa traveled to Asia, did pilgrimage and went to Tibet where she helped at Lama Norlha's monastery. When it was time, Lama Willa returned to New York and went into the three year retreat, eventually completing two consecutive retreats. Upon finishing her second three year retreat, in 1999, she and all the other participants received the title "lama." At an official ceremony, all the participants, including those who had previously completed the three year retreat, were called back to the monastery in order to officially receive the title "lama." This was the first time Lama Norlha Rinpoche officially bestowed the title "lama" to the participants of the three year retreat.

Lama Willa's encounter with Buddhism is also characteristic of Nattier's "Elite Buddhism" classification. Her ethnicity, socioeconomic background, level of education, (she is currently completing a $\mathrm{PhD}$ degree), as well as the availability of time and resources to travel abroad are typical characteristics of members of "Elite Buddhism." Her personal story also illustrates the major demand driven characteristic of "Elite Buddhism," where the interest in the tradition is actively sought out by the recipient, who travels abroad and brings back the tradition with them (Nattier, "Visible" 43). 


\section{The Retreat Center}

Wonderwell Mountain Refuge is affiliated with Natural Dharma Fellowship, an organization founded by Lama Willa. The retreat center is located in a rural forested area 2 hours from Boston, in Springfield New Hampshire. The retreat house is a large twostory building, with a meditation hall, kitchen, 2 dining areas, 15 bedrooms, and 13 bathrooms, as well as an outdoor porch with an impressive view of the White Mountains. Throughout the house, several Buddhist elements of the Tibetan tradition can be found. Large thangkas of Tibetan Buddhist deities such as Green Tara, Sakyamuni Buddha and others could be observed hanging from almost every wall. Tibetan ritual drums, singing bowls, gongs and statues of deities were also found throughout the building. Each of the 15 rooms was named after Sanskrit or Tibetan Buddhist terms. The room I stayed in was called "Dakini," named after the Tibetan Buddhist mythical female embodiment of enlightened energy.

The meditation hall is spacious, with fireplaces at either end of the room, thangkas hanging from the walls, Tibetan ritual drums, and singing bowls. Although there were Tibetan Buddhist ritual elements and religious decorations, it was somewhat minimalistic compared to the traditional ornate Tibetan Buddhist aesthetic. I did not observe a traditional shrine room, or altar, with incense, saffron water, candles, and other such offerings that are made to the deities. Meditation cushions were arranged in a circle, where the lama's seat was differentiated from the other cushions by having an extra square cushion (zabuton) to provide a little more height. A large singing bowl was placed in front of the lama's cushion. Extra cushions and blankets were piled up along the walls. 
Fig. 3 Meditation Hall at Wonderwell Mountain Refuge

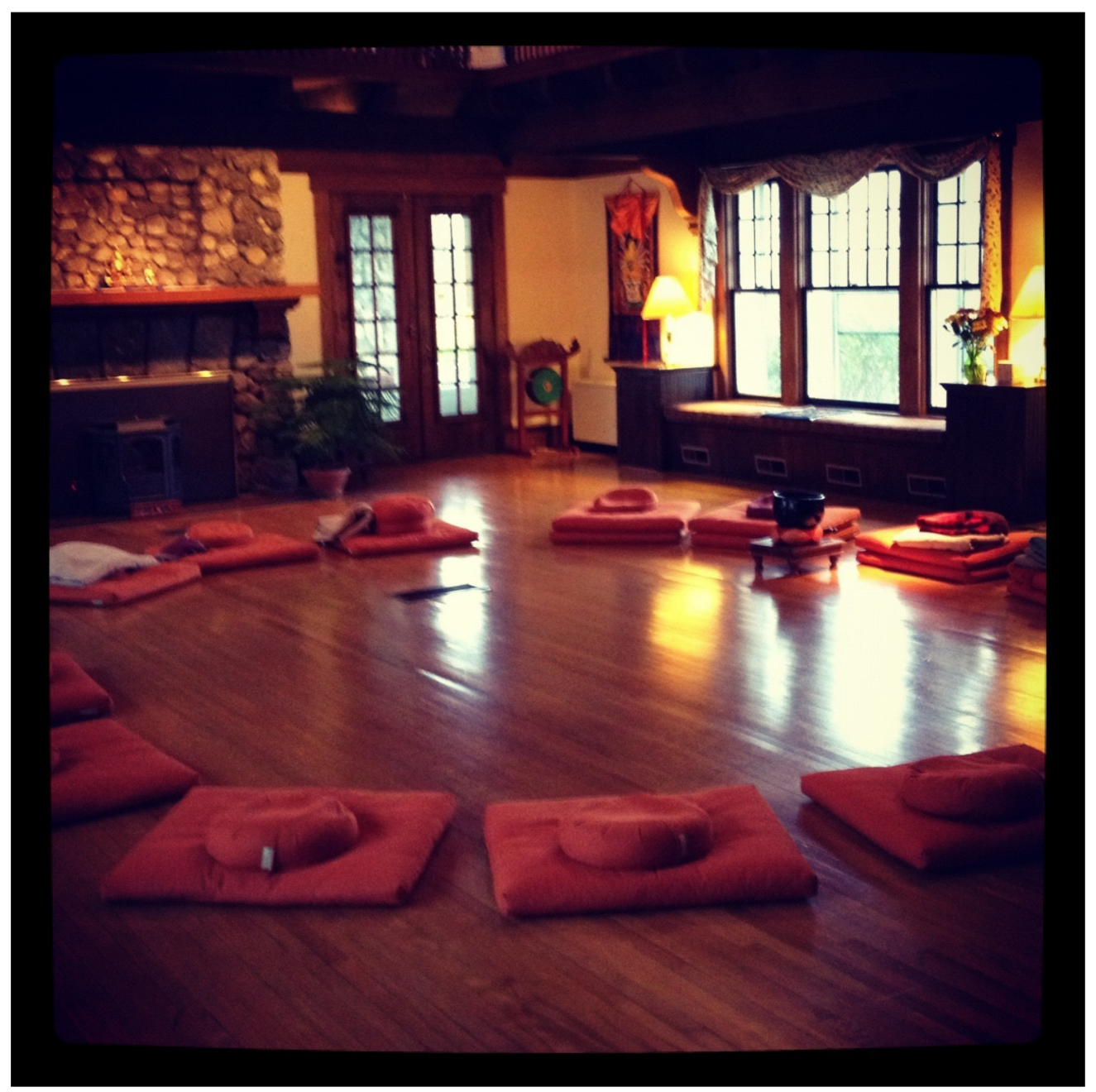

\section{The Retreat}

The retreat I attended at Wonderwell was titled "Mindfulness in the Mountains," co-sponsored by Lama Willa's organization Natural Dharma, and Mountain Spirit, an international holistic wilderness school, whose mission is "to facilitate one's connection to the natural environment, each other and a deeper connection to one's self' (Mountain Spirit Institute). The weekend retreat was a blend of meditation practices and outdoor sport experiences, where according to the description found on the Wonderwell website: 
Lovers of nature and outdoor sports will come together to adventure without and within. Led by a unique team of experienced world-class outdoor adventurers and experienced meditators, this weekend will provide room for exploring the layers of self-knowledge possible through adventuring.

The weekend consisted of two days of all-day outdoor activities, where each day participants had the option of choosing from hiking, kayaking or rock climbing, for each of the days. During these activities, different meditation practices were done through an exploration of nature and the outdoors and the techniques pertinent to each of the sport activities. My activities of choice were hiking on the first day and rock climbing on the second day.

A total of 15 people attended the retreat, including two meditation instructors, two sport instructors, two staff members, and Lama Willa. A young male in his late twienties whom I had met at Lama Makransky retreat two weeks prior, was also present at this retreat. A young female, in her late thirties, a male and his teenage son, an older man and an older woman were among the participants. All participants were non-Asian, Caucasian westerners. Due to the outdoor and sports oriented nature of the retreat, it was predominately a younger demographic. Despite the age differences among this group, their ethnicity, socioeconomic backgrounds, availability of leisure time, and levels of education, all make this group of participants characteristic of Nattier's "Elite Buddhism" ("Visible" 43).

Lama Willa's style of teaching is very flexible. This particular retreat, which might be characterized as non-traditional, is an example of her ability to teach to different audiences in different contexts. Through her organization, Natural Dharma Fellowship, 
Lama Willa offers three different practice tracks for three different types of audiences. The beginner's track includes activities that are open to people of different religious backgrounds, Buddhist or non-Buddhist. This particular track includes events such as the weekend retreat that I attended, which had no emphasis on particular Buddhist practices and rituals, but which provides general techniques based on Buddhist concepts that are relatable to people of different backgrounds and faiths, Buddhist or non Buddhist. According to Lama Willa, these types of activities and events provide access to people who otherwise would be driven away by the unfamiliar rituals and prayers associated with traditional Tibetan Buddhists practices. The intermediate track, as she describes it, "is for people who are Buddhists, but are attracted to non-elaborate practices, such as shinay meditation, lhatong and bodhicitta practices" (Miller). Lastly, the Vajrayana track is for those people who want to do more advanced and traditional Tibetan Buddhists practices, such as ngondro, chanting, and tsok for example.

Lama Willa remained an ordained nun for 15 years before she gave up her vows and gave back her robes. She felt that her robes and her status as an ordained nun was very restricting and separated her from students. Now, a lay lama, she only wears her lama robes in the more traditional setting such as the Vajrayana retreats or related activities. However in other settings, such as activities for the beginner's track, like the retreat I attended, she does not wear robes. In the same manner, she reverted her name back to Lama Willa instead of using her Tibetan name, Lama Palmo. She felt that in certain settings where she was teaching, people could not relate to her Tibetan name, people could not remember her name, and some could not even pronounce it. 
These are also examples of how she makes herself and her teachings approachable to different audiences and different contexts.

While in a traditional contexts such as a Vajrayana retreat, Lama Willa would limit her teachings to the traditional Kagyu lineage teachings and commentary; in other settings, such as the retreat I attended, she incorporates teachings from other spiritual traditions. The flexibility and openness in her teaching style, alongside her ability to remain traditional, allows her to reach out to different audiences and communicate Buddhist teachings in different contexts. Her teaching style and approach is an example of the development of Buddhism in the west, which strives to reach a balance between traditional teachings and concepts, and their adaptability to the western context. 


\section{Reginald Ray}

Personal Interview

Ray's Private Residence

October 29, 2012

Boulder, Colorado

Reginald Ray, or "Reggie" as he is better known, was born in New York City but grew up in Darien, Connecticut. His father was Christian, who Ray recalls as being "quite religious." His mother was not religious, however, she had told Ray's father "she was a Buddhist even before they got married." While not formally a Buddhist, "she had that kind of mindset" (Ray, "Personal Interview"). From a very early age Ray became interested in Tibet:

From a young age, eight or nine years old, I was fascinated with Tibet. I read National Geographic, anything I could get my hands on. I started having dreams about Tibet. They were the most compelling thing in my life. (Ray, "And Sparks" 27)

He attended Williams College with the intention of saving money to travel to Tibet, but he dropped out in 1962 before completing his degree and traveled to India. He then tried to go to Tibet, but since the Chinese Occupation had just taken place a couple of years before, he could not gain access (Ray, "And Sparks" 27). After spending time in India, Laos and Nepal, Ray made his way back to the United States where he returned to college and eventually went to graduate school to study Buddhism, receiving a $\mathrm{PhD}$ from the Divinity School of the University of Chicago in 1973.

While still at the University of Chicago in 1968, Ray found Chögyam Trungpa's book Born in Tibet, and from that moment on he identified Trungpa as his teacher, though it was not until 1970, that Ray finally met him: “...he didn’t present himself as a 
Buddhist. He presented himself as teaching about human life... I told him I wanted to be his student in 1970, and he said, 'yeah lets do it"” (Ray, "Personal Interview"). In 1971, Ray went to India on a Fulbright fellowship, where he spent a year studying Tibetan. Once in India, at the recommendation of his teacher Trungpa Rinpoche, he went to see H.H. the $16^{\text {th }}$ Karmapa, from whom he received refuge, as well as from Kalu Rinpoche. However, as Ray states, “...the real refuge was with Trungpa Rinpoche and the path of meditation he was offering" (Ray, "Personal Interview"). This reflected the nature of Ray's relationship with his teacher Trungpa Rinpoche. As he recalls:

... Trungpa Rinpoche during his lifetime, he was the most important person in my life, even though I was married and there were all sorts of things going on. He was, he knew me, we spent time together, he knew the ins and outs of my mind, my neurosis, my emotional makeup... (Ray, "Personal Interview")

In 1974, Ray moved to Boulder Colorado to join Trungpa Rinpoche at Naropa Institute (now Naropa University), where he became a full-time faculty member and the Chair of the Buddhist Studies Department.

Once more, as with the previous lamas, Ray can be classified within Nattier's category of "Elite Buddhism" in terms of ethnicity, socioeconomic status, and high level of education. Ray's encounter/involvement with the Buddhist tradition is also characteristic of "Elite Buddhism" since he actively sought out involvement with the Buddhist tradition. His initiative to travel to Asia, after developing interest in the tradition through reading is also characteristic of Nattier's "Elite Buddhism" since money and leisure time are necessary resources (Nattier, "Visible" 43). 


\section{Dharma Ocean}

After Trungpa's passing, Ray was actively involved with the Shambhala tradition. However, according to a letter released by Shambhala, Ray went beyond his role as an acharya (teacher) in the Shambhala tradition due to a number of issues, most importantly his giving of vajrayana pointing out transmission without authorization from either the Vidyadhara or the Sakyong. In 2006, due to the difference in perspective in regards to teachings between Ray and the Shambhala leadership, Ray left Shambhala to start his own organization Dharma Ocean, and began teaching on his own. Through the Dharma Ocean program, Ray now gives the Vajrayogini, Mahamudra,Bodhicitta, and Pele empowerments.

Ray is the Spiritual Director and founder of Dharma Ocean, an organization whose mission is " ... to embody, unfold, and widely offer the unique path to enlightenment taught by Chögyam Trungpa Rinpoche, creating a living continuity of the practicing lineage in our time" (Dharma Ocean Foundation). According to Ray, Dharma Ocean is based on the teachings of Trungpa Rinpoche, as well as Ray's personal experience and extensive practice. As it has been discussed in Chapter 3, Trungpa had appointed a regent to succeed him, however this passing down of the authority was not successful. Due to the events that took place after the passing of Trungpa and the failed succession by the Regent, there was not official passing of the Regent's lineage to any of Trungpa's other senior students. However, according to Ray, Trungpa had made it clear to him as well as other senior students that he wanted them to carry on his lineage. Nevertheless, without official public recognition by either Trungpa or the Regent, senior students such as Ray, were on their own. Having studied and practiced with Trungpa for 
more than four decades, Ray felt that Trungpa's lineage was not being maintained, and that the new leadership was not carrying out the teachings the way Trungpa taught them, it was up to him “keep Rinpoche's lineage alive.” For this reason, Ray developed Dharma Ocean, an organization with practices and teachings based on the traditional aspects of Trungpa's lineage, but which also integrates innovations based on his own personal experience and practice.

Crestone, Colorado, is home to Dharma Ocean's retreat center, where retreats such as the month-long Dathün are offered to practitioners. I was invited to participate in the winter month long Dathün retreat, but due to time constraints I was not able to do so. However, at Ray's request, in order to get a taste of his teaching style and the nature of his teachings, I completed a 2-volume audio-recorded program titled "Your Breathing Body."

Each volume had a total 10 CD's where each CD was one section. Each section was divided into three main parts: 1) The conceptual underpinning, or the view of the practice, 2) The description of the practice and its use, and 3) Guided meditation. Volume 1 covered beginner's practices open to anybody, drawing mainly from the Tibetan Buddhist tradition, but also drawing from other indigenous or native traditions. Even though the Buddhist aspect is present throughout the program, it is presented in a subtle way, where Buddhist terms, which are perhaps foreign to beginners, are minimally used. However, Buddhist concepts, such as ideas of the self, desire, attachment, karma, the Four Noble Truths, Buddha nature, and enlightenment, to name a few, are woven into the practices and their usage gradually increases throughout the program. 
Towards the end of the program, Ray introduces the concept of the studentteacher relationship within Buddhism, and even mentions his own teacher Trungpa Rinpoche and his concept of "Spiritual Materialism." Ray places himself and his program within the Buddhist tradition and the Buddhist lineage. He starts by covering the life story of the Buddha, the different ways of practicing found in Buddhism -lay versus monastic, Vajrayana lineage, Tibetan Buddhism in the west—and finally the lineage of Trungpa Rinpoche.

Most characteristic of Ray's teaching style and approach is his adaptation of Tibetan Buddhist teachings to the western context for a western audience, following the example of his teacher Trungpa Rinpoche. Ray expresses the need for the adaptation and transformation of the practices by getting rid of the "cultural trappings" present in the tradition:

...what lamas brought to the west, while it contains the very profound and transformative practices and teachings of Vajrayana Buddhism, at the same time what they brought was also mixed up with all kinds of Asian values ...(Ray, "Your Breathing Body" Vol. 2)

He emphasizes this very point by making reference to Trungpa Rinpoche and his approach to teaching Buddhism in the west:

...He taught Buddhism not as a Tibetan thing, not as identified with Tibetan forms and Tibetan ways of doing things. He taught it rather as a series of practices to liberate the human being that we are at this moment, whatever our cultural form... he retained the core practices of Tibetan Buddhism. It is important that these practices really were not Tibetan; they go back to India, to the siddhas... He let the cultural trappings go...he felt they were impediments to western practitioners. He himself did not dress in robes; he wore a business suit, which at that time was rather outrageous for a spiritual teacher.... (Ray, "Your Breathing Body" Vol. 2)

Ray has modeled his approach and style of teaching after that of his teacher Trungpa 
Rinpoche. He does not make used of titles, robes and thrones, and what he refers as 'cultural baggage,' since he finds them detrimental to the development of Tibetan Buddhism in the west. He presents himself as an ordinary person to whom students can relate on a deeper level. His teachings are presented in the "ordinary everyday language of our modern world," while at the same time covering the entire path of traditional practices such as Dzogchen, darkness practice, and consort practice. According to Ray, he has modified the delivery of the teachings and practices in ways that makes them more accessible, while maintaining their integrity of the teachings and connection to the lineage of his teacher. 


\section{Lama Karma Chötso}

Personal Interview

November 1, 2012

Kagyu Shedrup Choling

Lama Residence and Tibetan Buddhist Center

El Portal, Florida

Lama Karma Chötso was brought up in a Protestant Christian family in North Dakota. She lived in a small farming community. She describes her early childhood experience of religion as being characterized by religious tolerance and recalls how when one of the only two churches in town fell apart, "the whole town got together and decided that it would be best if they all came together and just called it the Unitarian Church. They just said that it was the unification of the Presbyterian and the Methodists Church."

Later, as a young woman, Lama Karma Chötso came to feel the need to learn how to meditate, and first went into the Muktananda center in New York City. However, as soon is she walked in, she turned around and walked away with the conviction that it was not the place for her. Shortly after, in 1982, she met a man who had just come back from India after having attended the cremation ceremony of H.H the $16^{\text {th }}$ Karmapa. Three weeks later the man called her and invited her to attend the Kalacakra empowerment that was going to be given by Kalu Rinpoche. And so she did. At the time Lama Karma Chötso was working in New York City for a labor arbitrator. As soon as she met Kalu Rinpoche, she felt she had found what she had been looking for. As she recalls:

... he walked in and he sat up there and he started talking, and something in me said he has it, what he has is what I need to have, which was enlightenment of course, and whatever I have to do to get it, that is what I am going to do, because this is the real thing, it felt really genuine...

The second day of the Kalacakra empowerment she took refuge vows with Kalu 
Rinpoche. When she received her refuge card, her name was written in Tibetan, and not being able to read it, she asked someone what is said. The young man who was sitting by her side told her how her that refuge name was the name Kalu Rinpoche usually gave to women who would go on to become nuns. While at the time this seemed unlikely to her, four years later in 1986, right before going into the three year retreat, she took ordination with Kalu Rinpoche and Lama Norlha Rinpoche at Kagyu Thubten Chöling in upstate New York. The first time she heard about three year retreat was during the Kalacakra empowerment, and she immediately knew that it was what she wanted to do. During the four years that passed from when she met Kalu Rinpoche to the time she went into retreat, she continued to work in order to save money to pay for her expenses during retreat. In order to prepare herself for retreat she started the preliminary practices (ngondro) and learned to chant the texts for the morning and evening practices, and finally moved into the monastery about nine months before going into the retreat.

Lama Karma Chötso participated in the second three year retreat to be offered in at Kagyu Thubten Chöling. When she came out of the three year retreat in 1990, the title 'lama' had not yet been given. It was not until years later that she and other graduates of the three year retreat were called back for the ceremony where they were officially bestowed the title 'tripon lama,' or teaching lama, by Lama Norlha Rinpoche. After finishing her retreat, Lama Karma Chötso went on pilgrimage to India, Sikkim, Tibet and Nepal. She stayed in Nepal to study and practice the Dharma before her return to America. 


\section{Kagyu Shedrup Chöling}

In 1996, her teacher Lama Norlha Rinpoche instructed Lama Karma Chötso to stay in South Florida. She went on to establish Kagyu Shedrup Chöling (KSC), a Tibetan Buddhist center dedicated to the study and practice of the Dharma. KSC is located in El Portal, FL, in a small neighborhood right along the edge of Little River, surrounded by old growth trees, proudly calling itself a bird sanctuary. From the outside, KSC looks like any other house on the block, a charming one-story house, nested among different varieties of palm trees and other tropical vegetation. However, once you approach the doorway, a pile of shoes by the entrance gives the first indication that this is not a typical home. Once you walk through the door you step directly into the shrine room. The shrine room is characteristic of the ornate and colorful Tibetan style. Tibetan thangkas of Buddhist deities, such as Green and White Tara, Chenrezi, Medicine Buddha, Mahakala, and Shakyamuni Buddha hang on the walls. Pictures of teachers of the Kagyu lineage, such as H.H the $17^{\text {th }}$ Karmapa and Lama Norlha Rinpoche are also found. A main shrine and two smaller altars hold statues of the same Buddhist deities that are depicted in the thangkas. In front of the statues, rows of offering bowls are lined up containing traditional offerings such as perfumed water, flowerers, incense, candles, sweets, and shells. Across the room, opposite to the main shrine, there is a table holding a large singing bowl, a couple of Tibetan texts, a bell and dorje, and other Buddhist religious artifacts. To the right side there is a large Tibetan drum. This is the place where Lama Karma Chötso sits to teach and to do her own practices. Benches and meditation cushions are piled up along the walls. 
In the main house there is the shrine room, a room for guests, an office, a dining room and a kitchen. One of the rooms in the house is set apart for the Shambhala Group, a Buddhist group of the tradition of Chögyam Trungpa Rinpoche. In the backyard, behind the house, four traditional Tibetan stupas have been recently constructed. A stupa is a Buddhist monument, usually a bell-shaped structure that is traditionally used as a reliquary. Lama Karma Chötso describes the stupas as being "the representation of the enlightened mind of the Buddha" that are used for Buddhist practice which brings benefit and creates merit for oneself and others. The "stupa project" at KSC took about three years to complete. On the week of Dec $2-8^{\text {th }}$ the project culminated with the stupa consecration ceremony that was attended by the sangha, or the community of practitioners, as well as the larger KSC community.

Fig.4 Panoramic view of the Shrine room at Kagyu Shedrup Chöling

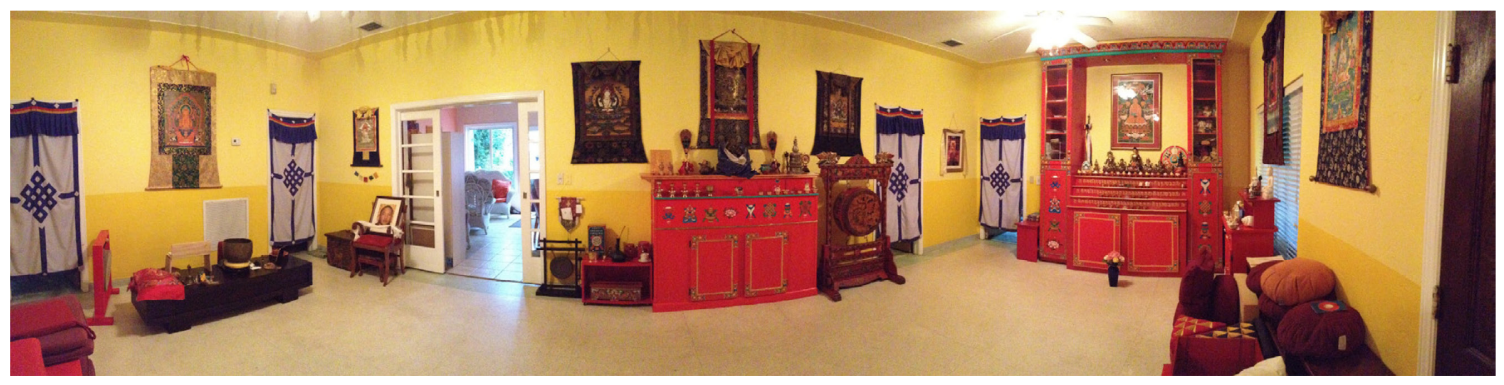


Fig. 5 Stupa Garden of Merit at Kagyu Shedrup Chöling

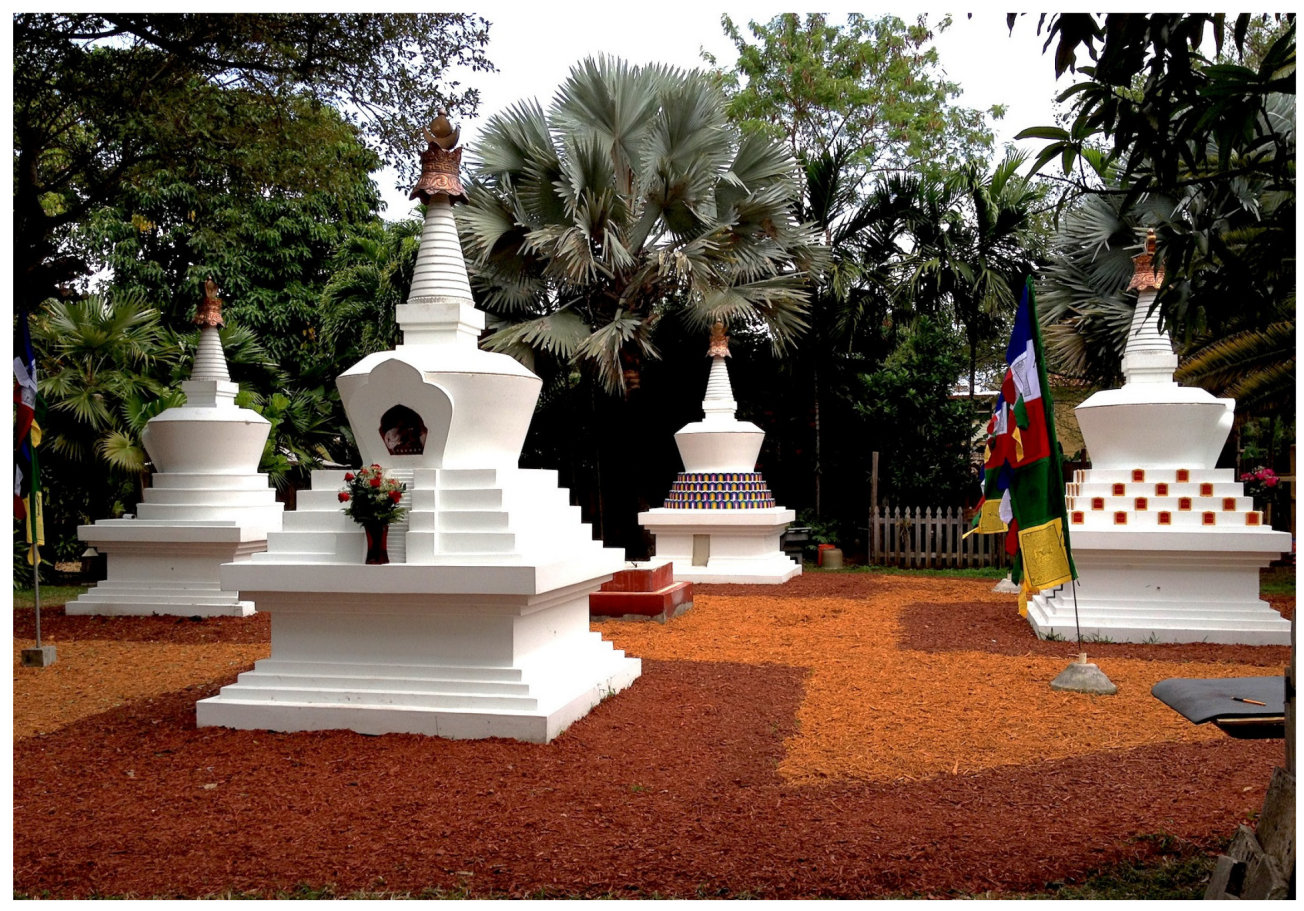

\section{Activities}

The sangha at KSC is very diverse in age and ethnicity. Practitioners rage in age from 10 to $70+$ years of age, but the average practitioner at is 20-30 years old. In terms of ethnicity, most of the practitioners are of various Hispanic backgrounds, with a few Caucasians, and one person of Asian origin. The diversity among practitioners is mostly due to the demographics of Miami itself, where the center is located. While in terms of age and ethnicity the group is not characteristic of the "Elite Buddhism" category as described by Nattier, in terms of socio-economic background and educational status they fit within the elite category. Most members at the center have high levels of education, having completed advanced university degrees or taken college level classes. Occupations found among the members include lawyers, psychologists, doctors, college professors, nurses, and other occupations that would be categorized as belonging to the 
"middle" and "upper-middle" class. Some of the practitioners have also attended meditation retreats offered at KSC as well as other out-of-state centers affiliated with the center, being characteristic of Nattier's category, since money and leisure time are necessary resources for such activities (Nattier, "Visible" 43).

Lama Karma Chötso offers different activities at KSC, including traditional chanting and practices for more advanced practitioners, as well as a meditation class for beginners. During the course of the five months that I attended the meditation class, Lama Karma Chötso also started a one-day intensive meditation retreat that would take place once a month. The people who attended the intensive retreats were members of the beginner's meditation group.

The first intensive meditation retreat for beginners took place Sunday August 25, 2012. The retreat started early in the morning at $7 \mathrm{am}$ and ended that same day at $7 \mathrm{pm}$. A total of 14 people attended the retreat, with 6 males and 9 females, including myself. The retreat was characteristic of Lama Karma Chötso's approach and style of teaching, which as she describes it is approach is very traditional and solidly within the Kagyu tradition.

The retreat started with the set up of the shrine. Offering bowls had to be filled with saffron water as well as other traditional offerings such as rice, incense and flowers. Once the shrine was set up, and after having performed prostrations, participants proceeded to do the daily practices; in this case the Green Tara sadhana was chanted in Tibetan. Silent meditation and contemplation on Buddhist concepts such as the non-self were the focus throughout the day. Lama Karma Chötso teaches using traditional Buddhist terms, both in Tibetan and Sanskrit. When teaching about complex Buddhist 
concepts such as the non-self or the five aggregates, she uses the traditional commentaries found within Tibetan Buddhist literature.

The stupa project, especially the weeklong events that took place before the final consecration ceremony are exemplary of her traditional style and approach. Lama Karma Chötso made sure that all activities and ceremonies needed in order to consecrate the stupas were done scrupulously and in the traditional manner. For this purpose, Lama Karma Chötso invited a Tibetan Rinpoche as well as two other western lamas from KTC, her home monastery. The week included three full days of all day chanting for the consecration of all the ritual objects that were placed inside the stupas as well as the initiations of the practices of Green Tara, Medicine Buddha, Chenrezi and Guru Dragpo, all of which were officiated by the visiting Rinpoche.

Overall, the activities of this group under the guidance of Lama Karma Chötso are those of traditional Tibetan Buddhism such as prostrations, vows, and visualization practices. Shrine room activities such as setting up appropriate offerings of incense, flowers, rice, saffron water and so forth are common, as well as rituals such as fire pujas, butter lamp offerings, and chanting practices of various Tibetan Buddhist deities such as Medicine Buddha, Chenrezi, and Green Tara. Tibetan holidays such as Losar, or the Tibetan New Year, are also celebrated at Lama Karma Chötso’s center. 


\section{CHAPTER V: LOCATING THE LAMA WITHIN AMERICAN TIBETAN \\ BUDDHISM.}

\section{Defining 'lama'}

Before engaging in a discussion about western lamas, it is necessary to define and discuss the term "lama" and its use within Tibetan Buddhism in general. Donald Lopez discusses the origin of the term "lama" as the Tibetan equivalent for the Sanskrit term guru, or teacher:

With the introduction of Buddhism in the seventh, eight, and ninth centuries, Tibetan monks and visiting Indian panditas undertook the task of translating Buddhist texts form Sanskrit into Tibetan, in the process inventing hundreds of neologisms. When these exegetes came to decide upon a Tibetan equivalent for guru, the Sanskrit term for teacher, they departed form the storied penchant for approximating the meaning of the Sanskrit and opted instead for the word "lama" (bla ma). Here they combined the term $l a$ with $m a$, the latter having a least here meanings: a negative particle meaning "no" or "not," as a sustentative indicator (as in nyi ma, "sun," or srung ma, "protector"), and as the word for "mother." Subsequent Buddhist etymologies, drawing on the meaning of la as "high" rather than its pre-Buddhist usage as "soul," were then construed which explained la ma as meaning "highest' (literally "above-not," that's, "none above") or "exalted mother." Lama came to be the standard term for one's religious teacher... (Lopez 18)

Lama, therefore, is the term used to refer to a spiritual teacher. However, as Lopez has noted, the title 'lama' is also given to those who are recognized as incarnations of great teachers within the Tibetan Buddhist lineages, the most popular example being the Dalai Lamas (19). These types of reincarnate lamas are also known as tulkus. Therefore, a distinction can be made in the usage of the term "lama;" "lama" may refer to an incarnation, those who inherit the title from a pervious incarnation(s), and those who "earn" it in this life time. 
My thesis makes use of both these meanings of the term "lama." However, a distinction in meaning is made when talking about Tibetan lamas who are of Tibetan heritage, and western lamas, those of non-Asian heritage. When referring to Tibetan lamas, the use of the term here implies both a spiritual teacher, but also as an incarnation. However, when referring to western lamas, the term is taken to mean solely spiritual teacher, and does not denote a status as a tulku or incarnation. While there have been some westerners who have been recognized as tulkus or reincarnate lamas, itself an important area demanding further study, my thesis is only concerned with western lamas who are not incarnations, and the use of the term here is therefore limited to "spiritual teacher."

When asked to define the term "lama," Lama Karma Chötso described it as someone who is " able to guide people in their practice." Lama John Makransky, being a professor of Buddhist studies as well as a spiritual teacher of the Tibetan Buddhist tradition, uses the title "lama" in order to make a distinction between these two approaches of teaching. As he explained it to me, in certain settings:

... people should realize that what you are teaching, and the way you are teaching, it is not just something that a professor does.... It means that what we are doing is not academic and not merely intellectual. We are exploring into the heart of practice, into the heart of the possibility of awakening, it is a designation that signals to people that this is what we are doing here.

According to Lama Willa, the title "lama" refers to someone who is officially recognized as a teacher within the tradition, someone who teaches techniques, such as meditation practices "to help others see the nature of their mind." While Ray choses not to use the title "lama" he does use the Sanskrit term "guru," which he describes as teacher or 
spiritual friend (Saskrit kalyanamitra) who guides one on the spiritual journey. All of these understandings of the term 'lama' point to the use of the term as it has been previously discussed, referring to a spiritual teacher.

\section{Lamas as Catalyst of Change}

In order to talk about change within the Tibetan Buddhist tradition in America, we must first identify the agents of change. My thesis focuses on leadership roles within the Tibetan tradition, particularly the role of the lama as an influential figure that continuously shapes the development and transformation of the Tibetan Buddhist tradition in the west. The lama, holding an authoritative power, can act as a catalyst for change within their group. Therefore, the lama is seen as a central figure in the overall process of adaptation and transformation of the Tibetan Buddhist tradition in America.

In order to understand how change and adaptation takes place within the Tibetan Buddhist tradition in America, the role of the lama as an authority figure and therefore a facilitator of change, needs to be addressed. To this end, three relevant areas regarding the role of the lama within the transforming tradition are identified: 1) the basis of authority of the lama, or how authority is obtained;2) the use of such authority as a tool for change; and 3) transmission of the teachings and lineage.

\section{Basis of Authority}

Weber proposes three types of legitimate authority: 1) Rational, 2) Traditional, and 3) Charismatic (Weber, On Charisma 46). The basis of spiritual authority of Tibetan 
lamas (of Asian heritage) and western lamas (of non-Asia heritage) can be classified in two different ways according to Weber's Authority Types, traditional and charismatic.

One way to interpret the basis of authority of a Tibetan (incarnate) lama is through the process by which they are recognized as an incarnation, and therefore placed into a position of spiritual authority. Weber addresses this issue in his discussion of the routinization of charisma, and the process by which a charismatic leader is succeeded. Weber uses the example of the process by which incarnate lamas are chosen, in particular the succession of Dalai Lamas. He describes such process of succession in the following manner:

...The search for a new charismatic leader on the basis of criteria of the qualities which will fit him for the position of authority. This is to be found in a relatively pure type in the process of chose of a new Dalai Lama.... (On Charisma 55)

However, as the process of succession becomes established, as in the case of the institution of incarnation or "the practice of identifying the successive rebirths of a great teachers" as that has been practiced in Tibet since at least the fourteenth century (Lopez $18)$,

...the legitimacy of the new charismatic leader is bound to certain distinguishing characteristics; thus, to rules with respect to which a tradition arises. The result is a process of traditionalization in favor of which the purely personal character of leadership is eliminated... (Weber, On Charisma 55)

Therefore, as Weber describes it, this process becomes traditionalized through its perpetuation. The basis of authority of the Tibetan lamas is founded on traditional grounds, on an already established tradition and its legitimacy. I chose to categorize the basis of authority of the Tibetan (incarnate) lamas as characteristic of Weber's "traditional authority" category. As the Tibetan lamas come to the west, the patriarchal 
system of traditional authority is also perpetuated by westerners who legitimize the spiritual authority of the Tibetan lamas based on tradition: "The Tibetan lamas promised authenticity, purity, and a direct connection with the Symbol of Tibetan, with all its connotations..." (Bishop 97). westerners perceive Tibetans as part of an already established system that recognizes their authority as legitimate. They represent a direct and unblemished lineage of spiritual power and spiritual teachings. It is an inherent and inherited spiritual authority where the Tibetan lama "is presented as being beyond critique. The ordinary western devotee does not presume to criticize...” (Bishop 102)

Distinct from the authority of Tibetan lamas, the authority of western lamas is not based on traditional system. Rather, the basis for the legitimacy of their authority is based on charisma, exemplifying Weber's concept of "charismatic authority." Weber defines "charisma" as a "certain quality of an individual personality by virtue of which he is set apart form ordinary men and treated as endowed with specifically exceptional... qualities...regarded as ...exemplary" (On Charisma 48). In the case of western lamas, the completion of the three year retreat is one way in which an individual gains such exceptional and exemplary qualities, and is a process through which their authority is legitimatized. While it may sound somewhat contradictory, since Weber states that charisma cannot be "learned" or "taught", it can only be "awakened" and "tested" (On Charisma 58). However, the three year retreat can be seen as the process through which charisma is in "awakened" and even "tested."

Reflecting upon the routinization of charisma, Weber also discusses the problem of succession of a charismatic leader and the possible solutions to the passing down of charismatic authority. One of the ways the passing down of charismatic authority is 
accomplished is by the transmission of charismatic authority through ritual means. Weber describes the process in the following way:

...The concept of charisma may be transmitted by ritual means from one bearer to another or may be created in a new person... In this case the belief in legitimacy is no longer directed to the individual, but to the acquired qualities and to the effectiveness of the ritual acts.... (57)

Therefore, the legitimacy of authority is based on the ritual through which the exemplary qualities are acquired, particularly though the three year retreat. Thus, by completing a three year retreat, and the rituals and practices associated with it, a person is set apart from ordinary people and is perceived as having unique and exemplary qualities, legitimizing that person's spiritual authority, through both a process of personal awakening and ritual efficacy.

\section{The Three-Year Retreat}

The first three year retreat for westerners was offered in 1974 in France by Kalu Rinpoche (Lorien 137). By 1982, two three year retreat centers were established in the west, one in Canada and one in the United States. The first retreat that was established in the in United States is located in Wappingers Falls, NY, and its part of Kagyu Thubten Chöling Monastery, where Lama Willa and Lama Karma Chötso completed their three year retreat.

There are many rituals and practices associated with the three year retreat, among them empowerments and transmissions, which are part of the passing down of the teachings and therefore the lineage: 
Before entering retreat, prospective retreatants must undergo a series of ritual ceremonies or empowerments (dbang bskur [wang-kur]) performed by the lineage holder or authorized spiritual teacher. In Vajrayana, empowerments are indispensable, conferring the necessary authorization and functioning as the entryway into Tantra. (Lorien 174).

Traditionally, those who successfully completed a retreat, whether lay or monastic, were given the title "lama." Lorien describes the role of those who had completed a retreat in Tibet:

...Students who successfully completed three year retreats would become Lamas or they might continue in retreat as monks or Yogis. Lamas were expected to serve their associated monastery and community at large not unlike a parish priest: conducting rituals, blessings, offering teaching, advise and counseling when requested; and at death conducting the proper ceremonies. (Lorien 137)

In the same manner, the aim of the three year retreat training in the west is to qualify westerners who would become lamas, to "perform traditional rituals and recitations and to guide western students in traditional mediation practices," an example of the passing down of the legitimization of spiritual authority through ritual means as it has been previously discussed (Wetzel 277).

\section{Case Study}

Chapter 3 provided a brief description of each of the lamas interviewed, and the circumstances or the process through which they became lamas. Lama Karma Chötso attended the second three year retreat at KTC, which was also the second retreat of its kind to be offered in the United States. Lama Willa attended the two consecutive retreats

that followed. While the title "lama" was not being officially given when Lama Karma Chötso finished her retreat, by the time Lama Willa finished her second retreat, Lama 
Norlha Rinpoche decided to hold an official ceremony to bestow the title. Lama Karma Chötso, as well as other graduates of previous retreats were called back in order to officially receive the title "lama." Lama Willa describes how being bestowed the title lama was a way of being officially authorized to teach, in a way legitimizing their spiritual authority.

While completing a three year retreat is one way through which spiritual authority is legitimized in the Tibetan Buddhist tradition in the west, it is certainly not the only way. As a student of Trungpa Rinpoche, Ray belongs to a movement that broke away from tradition. While Trungpa's spiritual authority was derived from a traditional system of authority, his movement and his transformation and adaptation of Buddhism in the west was based on Trungpa's charismatic authority. As it has been previously discussed in Chapter 2, Trungpa's movement, as any movement founded by charismatic figure, faced the problems associated with the succession of their founder. Although Trungpa sought to pass down his authority by appointing his own successor, the process was not successful. As Weber notes, in order for this method of succession of a charismatic leader to be successful, the designation of his own successor by the original charismatic leader must also be recognized on the part of the followers (On Charisma 55). Due to circumstances that have been previously discussed in Chapter 2, the members of his movement did not recognize the authority of Trungpa's appointed successor, Osel Tendzin. As Ray discussed with me during his interview, Osel Tendzin, as the appointed regent, was to pass down the lineage of Trungpa Rinpoche onto many of the senior students. A situation that would have established a system of legitimizing spiritual authority on the basis of designation, first by the original charismatic figure, and then by 
his successor. However, the regent's authority was challenged, and no official passing down of the lineage took place. Therefore, creating a situation where teachers such as Ray had to establish their authority through their own charisma, their personal virtues and exemplary qualities, rather than through official appointment or succession. Here, the relationship between the leader and his followers becomes a central aspect, since recognition on the part of those subject to authority is the basis for the validity of this type of charismatic authority (Weber, On Charisma 49).

Though Lama Makransky did not formally complete a three year retreat, independently and through his work with Lama Surya Das he completed extensive retreating during the summers as well as weeklong and weekend retreats throughout the year. At the end of a long summer retreat, Lama Surya Das installed him as a lama. Lama Surya Das, having completed two three year retreats, is an example of what has been described as the legitimization of authority through ritual means. Makransky's spiritual authority was in turn established by designation by Lama Surya Das, whose authority has already been established as legitimate.

These are examples of some of the different ways by which spiritual authority is legitimized in the Tibetan Buddhist tradition in the west. Some westerners may go through official training, such as the three year retreat, others may teach with the permission of their own teachers, while others, who through the organic development of their own practice and their relationships with their students, find themselves within new positions of authority. The diversity is reflective of the variety of ways that Tibetan Buddhism is being adapted and transformed in the western context. As the tradition continues to adapt and transform, it will give rise to new ways of legitimizing spiritual 
authority, which in turn will give rise to authority figures who will further continue to shape the tradition in ways that are particular to the western context.

\section{Preservation Versus Transformation}

As it is often pointed out, "historically whenever Buddhism has entered a culture, it had not only changed the culture, it has also been changed by it. This is the nature of Dharma translation and transmission" (Surya 378). Buddhism originated in India, but has traveled to different geographical areas, such as Tibet, China and Southeast Asia. Wherever Buddhism has been established, it has been transformed in ways that reflect the specific needs of the people and culture it finds itself in, through a process which happens over many generations. Despite the different cultural variations of the tradition, there is still a central element that we recognize as Buddhism: "The Dharma is always able to retain its essence while reinventing itself anew in order to remain applicable, accessible and relevant" (Surya 378). The development of the Tibetan Buddhist tradition in the west has not been any different, the fact that we have westerners teaching the Dharma, is an example of the adaptation and transformation of the Tibetan Buddhist tradition as it responds to the needs of the cultural context it now finds itself in.

A prominent characteristic of the process transmission has been "the tension between tradition or orthodoxy and adaptation or modernization" of the tradition in the west (Kornfield XXIII). Western lamas are particularly faced with this dilemma, since the ways they choose to teach and communicate the Dharma has a direct influence in the development of the tradition. Therefore, there are those who hold a traditionalist perspective, who want to preserve the "purity" of the tradition, and consequently see their 
role as preservers and sustainers of the tradition as it has been handed down to them. However, more commonly there are those who see transformation and adaptation as important aspects in the development of the tradition in the west. Teachers who share this view seek new culturally accessible ways of presenting the tradition in the west, while at the same time keeping the heart and the essence of the tradition. As expressed by Jack Kornfield, "this is the task of North American Buddhism: to bring the heartfelt practices and awakening of the Buddha home to our native soil and contemporary times in a useful way" (XII).

There are three prominent features that are characteristic of the adaptation of the Tibetan Buddhist tradition in the west; 1) discarding of uniquely Tibetan "cultural baggage"; 2) the incorporation of not only other Buddhist traditions, but other spiritual traditions; 3) The adaptation of Buddhist concepts and practices to make them more accessible to people of different backgrounds.

\section{Deculturalization}

Due to globalization, as different religious traditions become established in new places, "religions, like cultures and societies, are allegedly undergoing a process of detraditionalization - in relation to a broader process of modernization-otherwise labeled deculturalization or denationalization, consisting in the dissociation between religious systems and its traditional socio-cultural context" (Obadia 487). The process of detraditionalization and deculturalization is reflected in the efforts of some western Buddhists, who talk about getting rid of the "cultural baggage" associated with the Tibetan Buddhist tradition. They want to transmit the essence of the tradition, without 
necessarily transmitting its cultural adaptations, arguing that Buddhist teachings are "not limited by trappings of culture, language, or time" (Surya 378). Certain aspects of the tradition, such as ritual instruments, clothing, decorations, and furniture, are examples of these minor aspects that are seen as Tibetan adaptations, seen by some as not relevant or even not useful to the new cultural context. A perspective that is clearly reflected in Ray's teaching style:

...I do not call myself a lama and do not teach Tibetan Buddhism in its traditional form with the cultural trappings...I do not wear robes, do not sit on a throne, and do not have students prostrate to me. I present myself as an ordinary person who, perhaps, has something to teach others. ... I teach the dharma in the ordinary everyday language of our modern world; I do teach an entire path from the beginning up through Dzogchen, darkness practice, and consort practice. These are all Tibetan practices and nothing of their power has been sacrificed or watered down; at the same time, I teach them all as ways to become more deeply human... (Ray, "Personal Interview")

Ray's teaching style is based on the approach of his own teacher Trungpa Rinpoche, who in the same manner, although being a Tibetan lama he let go of the "cultural trappings" of the Tibetan Buddhist tradition:

...He taught Buddhism not as a Tibetan thing, not as identified with Tibetan forms and Tibetan ways of doing things. He taught it rather as a series of practices to liberate the human being that we are at this moment, whatever our cultural form... he retained the core practices of Tibetan Buddhism. It is important that these practices really were not Tibetan; they go back to India, to the siddhas... He let the cultural trappings go... he felt they were impediments to Western practitioners. He himself did not dress in robes; he wore a business suit, which at that time was rather outrageous for a spiritual teacher.... (Ray, "Your Breathing Body" Vol. 2) 
While Ray has transformed the tradition by dispensing of what he considers to be the cultural elements that are not relevant to the western cultural context, he considers that the essence, the heart of the tradition, is still present in his teachings ${ }^{1}$.

\section{Incorporation of New Elements}

The religious landscape of the United States offers a rather unprecedented phenomenon in the history of the development of Buddhism. We are in a situation where we find the different Buddhist traditions (e.g. Theravada, Mahayana, Vajrayana), as well as their cultural variations (e.g Thai and vietenamese Theravada, Japanese Zen, Tibetan Vajrayana) present to each other at the same time in the same geographical area (Gregory, 252). Furthermore, the presence of several different spiritual traditions, both eastern and western, such as Judaic Kabbalah, Contemplative Christianity, Islamist Suffisim, and Hindu Yoga, among others, are also part of the American religious landscape. Thus, an environment that has encouraged many Buddhist teachers to engage in dialogue, not only with other Buddhist traditions, but also with other religious traditions: "What was originally separate is being unified; what was originally unified is being expanded and diversified" (Rawlinson 123). As Rawlinson notes, a result of the dialogue and interaction between different spiritual traditions, is that:

... A large percentage of Western teachers have introduced new elements into their teaching and into their practice, sometimes from other Buddhist traditions; sometimes from other traditions altogether; and sometimes from their own experience. In fact, some of them have reinterpreted their tradition in the light of these extra elements, even to the point of trying to restructure the tradition entirely. (134)

\footnotetext{
${ }^{1}$ Chapter 3 has a more detail discussion of Ray's teaching style and approach.
} 
Lama Makransky speaks about how he is oriented to what he calls a "multi-faith" context. The retreats and teachings that he offers are not only attended by Buddhist of different kinds, and not exclusively by those who identify with the Tibetan tradition, but also by people formed in different religious backgrounds, such as Christianity, Judaism, as well as other religious traditions. He therefore he adapts the delivery of the teachings, to make them relevant to people in various contexts. An example of this was the use of religious figures from different spiritual traditions such as Jesus, Mother Theresa and Gandhi, during the practice of "spiritual benefactors," which allowed people of different religious backgrounds to relate to the practice ${ }^{2}$.

Lama Willa, in certain contexts, particularly in activities belonging to the beginner's track, ${ }^{3}$ will engage in non-traditional teachings such as incorporating elements from other spiritual traditions alongside Buddhist teachings. At one point during the retreat I attended, Lama Willa read a passage from a Native American story. When I later asked her whether incorporating other traditions into her teachings presented a conflict with the Buddhist tradition, she then told me that "if the wisdom is in line with our wisdom perspective, or with the wisdom perspective of Buddhist teachings, or close enough, I feel like is very beneficial to draw from other traditions, I don't think it is a problem myself." In the same manner, Reggie Ray incorporates teachings from other spiritual traditions. According to Ray, as one "practices enough of one tradition, when you look at another tradition, you can see right away when there are parallels." Ray talks about how he himself and his teachings are influenced not only by Zen and Theravada

\footnotetext{
${ }^{2}$ Chapter 3 provides a more detailed discussion on Lama Makransky's teaching style

${ }^{3}$ As it was discussed in Chapter 3, she has 3 different tracks of study, for which she will have different approaches.
} 
Buddhism, but also by other indigenous teachers and traditions, also seen in Ray's teachings, especially those that have to do with the body, such as the recorded program "Your Breathing Body."

\section{Adaptation}

Another element characteristic of the development of the Tibetan Buddhist tradition in the west has been the adaptation of traditional practices to make them more accessible to the western audience. The approach on the basis of adaptation stresses "essence more than form," where what is being taught is the essence of the Tibetan Buddhist tradition, but the ways of delivering are different in order to fulfill the needs of our cultural context (Surya 384). Rather than focusing on "complex, esoteric rites and arcane rituals," teachers are focusing on teachings that are relevant for daily life (Surya 384). Ray's approach is a reflection of this perspective:

I teach the dharma in the ordinary everyday language of our modern world; I do teach an entire path from the beginning up through Dzogchen, darkness practice, and consort practice. These are all Tibetan practices and nothing of their power has been sacrificed or watered down; at the same time, I teach them all as ways to become more deeply human.

Western teachers recognized the necessity of speaking in ways that are relevant to their audience and their context, reflected in the way Lama Makransky describes his own approach:

I do not consider what I'm doing something different from Tibetan Buddhism ... And yet as you saw during the course of the retreat, obviously what I'm doing is not the same thing that a Tibetan lama would be doing with Tibetans, in terms of commenting upon and guiding, explaining the theory, guiding the practice, in a traditional form, precisely in the traditional form with the traditional iconography and imagery and 
repeating in a way the standard explanation or much of what is being done in a form that Tibetans are familiar with, confortable with, fits them in many ways. So then obviously I'm not doing that, and if I did do that, it would be as if I was teaching for some other group, other than the group that is here

The adaptation of practice in these ways provides access to the tradition for people of different backgrounds. It provides accessibility to the practices and concepts found within Tibetan Buddhism in ways that are relevant to the western context.

\section{Transmission}

Perhaps "the image of an unbroken transmission of wisdom," also known as lineage, is one of the most central characteristics of Tibetan Buddhism (Bishop 100). In the Tibetan Tradition, lineage is seen as an "unbroken chain" of teachings that have been "handed down personally from the Buddha until today" (Surya 39). Hence, the Dharma has been transmitted in a way that the "most profound guidance and instruction in Tibet have been done orally, intimately passed from master to disciple, on a one-to-one basis. These teachings were privately held, going form generation to generation, creating a lineage of "ear whispered" sacred instructions (Surya 39). The lama is an essential figure in the transmission of the Dharma, and therefore of the lineage: "In order to receive full transmission of the Buddhist tradition, Tibetan lamas are still required to receive oral transmission of Buddhist scripture sand teachings from a qualified lama in the oral lineage; this is called lhung, or oral authorization" (Surya 39). It is through the teacherstudent relationship that the lineage has been transmitted to the present, from teacher to disciple, "like an inheritance" (Surya 39). Through ceremonies known as empowerments or initiations, "spiritual power is transmitted through the teacher to the student, a lineage 
of transmission by which the guru empowers the disciple to practice certain esoteric mediation" (Surya 40).

With the arrival of Tibetan Buddhism to the west, the first generation of Tibetan teachers sought to transmit their lineage in the traditional manner to their western students: "teachings were orally transmitted, along with esoteric initiations..." (Surya 38). Tibetan lamas personally trained their western students and transmitted their lineage to some of them. These students are part of the second-generation of western teachers who have been trained by Asian teachers and were "designated by their mentor[s] as one[s] who had understood the crucial point of the teachings in such a way that he or she is capable of teaching others" (Fields, "The Future" 25). The task of the secondgeneration western teachers has been to "further translate the Buddhist words, concepts, and forms of practice for transmission to Western students..." (Surya 381).

The passing down of lineage and the issue of succession in general has shown a great deal of variance from case to case, and these many ways in which teachers and their students have approached the issue of succession reflects the diversity of teaching styles within Tibetan Buddhism. Despite the diversity, two general modes of transmission can be recognized: 1) A system which relies on Tibetan lamas (of Asian heritage), in which western lamas serve as a link between western students and the Tibetan tradition; 2) A system in which the western lamas transmit the lineage directly to their western students.

The first model of transmission is characteristic of those western lamas who hold a traditionalist perspective, who want to preserve the "purity" of the tradition, and consequently see their role as preservers and sustainers of the tradition as it has been handed down to them. They see themselves as intermediaries between the Tibetan 
tradition and its Tibetan teachers, and their own western students. There is a sense that the Tibetan Buddhist tradition in the west, for the time being, will be linked to and depend on its Tibetan teachers.

For instance, the attitude is reflected in Lama Karma Chötso's style of teaching. While she has her own center where she instructs her students in meditation and teaches them traditional Buddhists concepts and practices, she ultimately refers her students to her Tibetan teachers. Some of her students who have become advanced practitioners started by practicing with her, but eventually she referred them to Kagyu Thubten Chöling, her home monastery, and to her teacher Lama Norlha Rinpoche, where they would receive the same training she herself received.

In the same manner, rather than creating a new movement, Lama Makransky has stated that he wants to create a "field of connectivity" where his students are aware that he is not separate from the wider Tibetan Buddhist tradition and all that it encompasses. Through his teachings, the students not only connect to him, they are also connecting through him to the Tibetan Buddhist tradition in general. Everything that Lama Makransky does, "is only an extension of the activity of [his] own teachers. It is not separate from that, it is not even independent of that."

The second model of transmission is prevalent among western lamas who see transformation and adaptation as important aspects in the development of the tradition in the west. As it has been previously discussed, western lamas who share this perspective seek to adapt the tradition in ways that are more accessible to westerners. In the same manner, they seek to transmit the lineage in ways that are appropriate to the cultural context in the west. Instead of depending on the Tibetans, western lamas in this model of 
transmission seek to pass down their lineages themselves directly to their students. In order to accomplish this task, some western lamas have created their own programs of study and practice.

Lama Willa, for example has created two programs through which she trains her students in the Tibetan Buddhist practices. The "Vajrayana Track" which is part of her organization Natural Dharma Fellowship, consists of a group of 20 self-selected students, and is an exclusive program through which she is passes down a body of teachings specific to the Kagyu lineage. The program requires students to complete several intensive retreats a year, as well as a strong practice commitment and regular check-ins with Lama Willa herself. She also created the "Margha Program," a two-year program in which students are instructed in the basic lineage practices of Mahamudra, Shamatha, Vipassana, and Lojong practices.

Ray emphasizes how the passing down of the lineage of the Dharma has to be done through western teachers, since "western teachers understand western culture in a way that Tibetans don't." Reggie Ray, through his organization Dharma Ocean, has also developed his own program based on Trungpa's three yana approach-Hinayana, Mahayana, and Vajrayana-consisting of many of the traditional aspects, but at the same time developing new ways that are relevant to the needs of his students. One example of Ray's approach has been the introduction of the feminine aspect as part of his lineage. Ray talks about how the traditional patriarchal system within the teacher-student relationship found in Tibetan Buddhism does not work in our modern context. According to Ray "women have to have women lineage holders to look up to, otherwise it is inherently disempowering for the women." 
Even though both Lama Willa and Ray have created structured programs through which their students learn the lineage practices associated with each of their traditions, they recognize that it takes more than that to achieve transmission. Ray describes it in the following manner:

...Everything that we are doing focuses not on delivering some abstract lineage or tradition, but on taking the tools of the tradition, and helping individual people make their own journey. The people that we worked with on that way are now teachers and they are helping other people, and that is actually how this lineage is being transmitted...

Here, the human connection of the teacher-student relationship remains a central aspect of the transmission of the lineage. Lama Willa similarly expresses how transmission is more than the passing down a lineage of teaching and practices

...[This is] the lineage of non-dual wisdom and compassion, which has nothing to do with texts, practices and rituals. It has to do with view, meditation and action, and the blessings and kindness of my teachers. It is an internal lineage. It has to do with training to embody a state of authenticity, and a commitment to wisdom and compassion in union. The lineage is invisible....Without this lineage, everything else is meaningless. 


\section{CHAPTER VI: CONCLUDING REMARKS}

My thesis has traced the study of Buddhism in the west in order to under to provide a historical context for the understanding of the arrival and development of Tibetan Buddhism to America. As it was demonstrated in chapter 2, scholarship in this area of study has mainly focused on the classification of the different types of Buddhism in the America, with a "two Buddhism" typology being the most prevalent approach to the classification of Buddhism in the west. While the scholarship in this particular endeavor of classification is vast and comprehensive, other areas pertinent to the study of Buddhism in the west remain understudied. One such area that has not been yet explored in depth is the study of leadership roles within Buddhism in America. My thesis sought to address this gap in the literature by studying the role of the lama within Tibetan Buddhism in the west, focusing on their influential role in the transformation of the tradition as it adapts to the American context.

My thesis argued how the role of western lamas holding a position of authority act as a catalyst of change in the overall process of adaptation and transformation of the Tibetan Buddhist tradition in America. To demonstrate how the western lama is an influential figure in the process of adaptation and transformation of the tradition three relevant areas discussed: 1) the basis of authority of the lama, or how authority is obtained; 2) the use of such authority as a tool for change; and 3) transmission of the teachings and lineage.

If history is an indication, Tibetan Buddhism in the west is still in a very early stage of development. It will take generations for Buddhism to establish itself and take root in America, developing its own cultural adaptations, as was the case in Asian 
countries like China, Japan and Tibet. However, as my thesis has demonstrated, we can observe major characteristics that point towards the development and adaptation of the tradition as it happens. We find ourselves in a crucial moment in the process of development, were we are witnessing the passing down of the lineage from secondgeneration western teachers onto third-generation western teachers- - those trained solely by westerners. It is crucial in that it will determine not only whether the different Tibetan Buddhist lineages are being successfully transmitted, but also more importantly whether they are being preserved. 
Bibliography

"A Complete History of the TBLC." Tibetan Buddhist Learning Center. Web. 05 Oct. 2012. <http://www.labsum.org>.

Adikaram, E W. Early History of Buddhism in Ceylon: Or, State of Buddhism in Ceylon D.S. Puswella, 1946. Print.

li Commentaries of the 5th Century A.d. Migoda, Ceylon:

Atkinson, Timothy V. "Western Buddhism: Past, Present and Future." International Journal of Buddhist Thought \& Culture 8 (2007): 149-63. Web.

Baldoquín, Hilda G. Dharma, Color, and Culture: New Voices in Western Buddhism. Berkeley, Calif: Parallax Press, 2004. Print

Barre Center for Buddhist Studies. 14 Dec. 2012. Web. < http://www.bcbsdharma.org/. >

Baumann, Martin. "Global Buddhism: Developmental Periods, Regional Histories, and a New Analytical Perspective." Journal of Global Buddhism 2 (2001): 1-43. Web.

------. "Protective Amulets and Awareness Techniques, or How to Make Sense of Buddhism in the West." In Westward Dharma : Buddhism Beyond Asia. Ed. Charles S. Prebish and Martin Baumann. Berkeley: University of California Press, pp 51-65

Basu, Sudeep. "Interpreting the Tibetan Diaspora: cultural preservation and the pragmatics of identity." CEU Political Science Journal 4.3 (2009): 419+. Academic OneFile. Web. 16 July

Bell, Sandra. "“Crazy Wisdom," Charisma, and the Transmission of Buddhism in the United States." Nova Religio: The Journal of Alternative and Emergent Religions 2.1 (1998): 55-75. University of California Press. Web.

Bell, S. (2002) 'Scandals in emerging Western Buddhism.', in Westward Dharma : Buddhism Beyond Asia. Ed. Charles S. Prebish and Martin Baumann. Berkeley: University of California Press, pp. 230-242.

Berzin, Alexander. Relating to a Spiritual Teacher: Building a Healthy Relationship. Ithaca, N.Y: Snow Lion Publications, 2000. Print

Bishop, Peter. Dreams of Power: Tibetan Buddhism and the Western Imagination. London: Athlone Press, 1993. Print.

Buddhaghosa, , and N A. Jayawickrama. The Inception of Discipline and the Vinaya

Bucchaghosa's na of , the Vinaya Commentary. 
London: Pali Text Society, 1986.

Bullis, Douglas, and Mahanama. The Mahavamsa: The Great Chronicle of Sri Lanka. Fremont, Calif: Asian Humanities Press, 1999. Print

Bstan-' dzin-rgya-mtsho, and José I. Cabezón, Answers: Discussions with Western Buddhists. Ithaca, N.Y: Snow Lion Publications, 2001. Print.

Carreon, Tara. "Another View on Whether Tibetan Buddhism Is Working in the West, by Tara Carreon." American Buddha. Web.

Coleman, James W. The New Buddhism: The Western Transformation of an Ancient Tradition. Oxford: Oxford University Press, 2001. Print

Cozort, Daniel. "The Making of a Western Lama." Ed. Charles S. Prebish. Buddhism in the Modern World. Ed. Steven Heine. New York: Oxford UP, 2003. 221-48. Print.

Crook, John. "Dangers in Devotion: Buddhist Cults and the Tasks of a Guru." Proc. of Conference 'The Psychology of Awakening II', Darlington Hall, UK. Oct. 1998. Web

Dewaraja, Lorna. "Cultural Relations between Sri Lanka and North India during the Anuradhapura Period." Sri Lanka Journal of Social Sciences 10 (1987): 1-19. Print

Dharma Ocean Foundation. 16 Dec. 2012. Web. http://dharmaocean.org

Dreyfus, George. 2005. "Are we prisoners of Shangrila?: Orientalism, Nationalism and the Study of Tibet." Journal of the International Association of Tibetan Studies $1(1)-1-21$.

Encyclopedia of Occultism and Parapsychology;_Trungpa Rinpoche, Chogyam (19401987). Ed. J. Gordon Melton. 5th ed. Vol. 2. Detroit: Gale Group, 2001.

Fields, Rick. 1994. "Confessions of a White Buddhist." 1994. Tricycle; The Buddhist Review, fall 1994. Web

----. "Divided Dharma: White Buddhists, Ethnich Buddhists, and Racism" The Faces of Buddhism in America. Ed. Charles S. Prebish and Kenneth K. Tananka. Berkely and Los Angeles: University of California, 1998. 196-206. Print.

----. How the Swans Came to the Lake : A Narrative History of Buddhism in America I Rick Fields. Boulder : New York: Shambhala ; Distributed in the U.S. by Random House, 1981. 
----. "The Changing of the Guard." How The Swans Came To The Lake. 3rd ed. Boston: Shambhala Publications, 1992. Print.

----. "The Future of American Buddhism." The Vajradhatu Sun 9.1 (1987): 1,22, 24-26. Print

Foundation for Active Compassion. 14 Dec. 2012. Web. $<\mathrm{http}: / /$ foundationforactivecompassion.org/>

Garfield, Jay L. "Buddhism in the West." Buddhism in the West. N.p., June 2010. Web.

Goldberg, Philip. American Veda: From Emerson and the Beatles to Yoga and Meditation : How Indian Spirituality Changed the West. New York: Harmony Books, 2010

Goldstein, Joseph. One Dharma: The Emerging Western Buddhism. San Francisco: Harper San Francisco, 2002. Print.

Gregory, Peter N. "Describing the Elephant: Buddhism in America." Religion and American Culture: A Journal of Interpretation 11.2 (2001): 233-63. University of California Press. Web.

Heine, Steven, and Charles S. Prebish. Buddhism in the Modern World: Adaptations of an Ancient Tradition. New York: Oxford University Press, 2003. Print.

Hickey, Wakoh S. "Two Buddhisms, Three Buddhisms, and Racism." Journal of Global Buddhism 11 (2010): 1-25. Web.

Hughes, Richard Seager. "American Buddhism in the Making.”, in Westward Dharma : Buddhism Beyond Asia. Ed. Charles S. Prebish and Martin Baumann. Berkeley: University of California Press, pp 106-119

Hodel, Brian. "Tibetan Buddhism in the West: Is It Working Here? An Interview with Alan Wallace." Tricycle: The Buddhist Review. Summer 2001: Web

Hori, Victor Sogen. 1994. 'Sweet -and-Sour Buddhism', Tricycle: The Buddhist Review, Fall 1994, web.

Karma Chötso, Lama. Personal interview. 1 Nov. 2012.

Kapstein, Matthew T. "Buddhism: Buddhism in Tibet." Encyclopedia of Religion. Ed. Lindsay Jones. 2nd ed. Vol. 2. Detroit: Macmillan Reference USA, 2005. 11501159. Gale Virtual Reference Library. Web. 25 Dec. 2012

Kaleem, Jaweed. "Buddhism In America: What Is The Future?" The Huffington Post. N.p., 14 June 2011. Web. 
Katz, Nathan. Buddhist Images of Human Perfection: The Arahant of the Sutta siddha. Delhi:

Motilal Banarsidass, 1989. Print.

-sprul, Blo-gros-mtha' -yas, and Ron Garry. The Teacher-Student Relationship: A Translation of the Explanation of the Master and Student Relationship, How to Follow The Master, and How to Teach and Listen to the Dharma. Ithaca, N.Y: Snow Lion Publications, 1999. Print.

Kornfield, Jack. "Is Buddhism Changing in North America." In Don Morreale (ed.), Buddhist America: Centers, Retreats, Practices. Sante Fe: John Muir Publications, 1988, pp. xi-xxviii.

Kulananda, . Western Buddhism: [new Insights into the West's Fastest-Growing Religion]. London: HarperCollins, 1997. Print.

Lavine, Amy "Tibetan Buddhism in America: The Development of American Vajrayana" The Faces of Buddhism in America. Ed. Charles S. Prebish and Kenneth K. Tananka. Berkely and Los Angeles: University of California, 1998. Print.

Layman, Emma M. C. Buddhism in America. Chicago: Nelson-Hall Publishers, 1976. Print.

Lopez, Donald S. Prisoners of Shangri-La: Tibetan Buddhism and the West. Chicago: University of Chicago Press, 1998. Print.

Lorien, Dawa G. "Assembled Identities: Transformation of Identity in Tibetan Buddhist Three-Year Retreats." Diss. California Institute of Integral Studies, 2012. Print.

Machacek, David W. "Immigrant Buddhism in America: A Model of Religious Change." Nova Religio: The Journal of Alternative and Emergent Religions 5.1 (2001): 6484. University of California Press. Web.

Makransky, John. Personal interview. 30 Sept. 2012.

Maraldo, John C, and Heinrich Dumoulin. Buddhism in the Modern World. New York: Macmillan, 1976. Print.

Marin, Peter. "Spiritual Obedience." Harpers Magazine. Vol. 258, No. 1545. February 1979. 43-59. Print

McLeod, Ken. "The Tree-Year Retreat." In Don Morreale (ed.), Buddhist America: Centers, Retreats, Practices. Sante Fe: John Muir Publications, 1988, pp. 209221. 
Midal, Fabrice. Recalling Chögyam Trungpa. Boston, Mass: Shambhala Pub, 2005. Print.

Miller, Willa. Personal interview. 14 Oct. 2012.

Mitchell, Scott A. "The End of American Buddhism: Toward a Transnational Perspective." Proc. of American Academy of Religion National Meeting, November, 2008, Chicago. Web.

Moat, John. "Chogyam Trungpa: Unmasking the Mind." Visionaries : The 20th Century's 100 most Important Inspirational Leaders. Ed. Satish Kumar - and Freddie Whitefield. White River Junction, Vt: Chelsea Gree Publishing, 2007

Mountain Spirit Institute. 14 Dec. 2012. Web. < http://www. www.mtnspirit.org/>

Nattier, Jan. "Buddhism Comes to Main Street." The Wilson Quarterly 21.2 (1997): 7281. Print.

----. "Visible \& Invisible; The Politics of Representation in Buddhist America." Tricycle; The Buddhist Review (1995): 42-49. Print.

----. "Why Buddhism, Why Now?" Civilization 6.6 (2000):. Web.

Numrich, Paul D. "Buddhism Comes to America." In Buddhists, Hindus, and Sikhs in America: A Short History. New York: Oxford UP, 2008. N. pp 1-41. Print.

----. "How the Swans Came to Lake Michigan: The Social Organization of Buddhist Chicago." Journal for the Scientific Study of Religion 39.2 (2000): 189-203. Web.

----. "Theravada Buddhism in America." The Faces of Buddhism in America. Ed. Charles S. Prebish and Kenneth K. Tanaka. Berkeley and Los Angeles: University of California, 1998. 148-61. Print

----. "Two Buddhisms Further Considered." Contemporary Buddhism 4.1 (2003): 56-77. Print.

Obadia, Lionel. "Globalization and the Sociology of Religion.", in The New Blackwell Companion to the Sociology of Religion. Hoboken: Wiley-Blackwell, 2010. Ebook Library. pp 477-497

----. "Tibetan Buddhism in France: A Missionary Religion?" Tibetan Buddhism in France: A Missionary Religion? Web. 17 July 2012.

Paine, Jeffery 1944-. Re-Enchantment : Tibetan Buddhism Comes to the West. 1st ed. ed. New York: W. W. Norton \& Company, 2004.

Prebish, Charles S. American Buddhism. North Scituate, MA: Duxbury, 1979. Print. 
----. "Ethics and Integration in American Buddhism." Journal of Buddhist Ethics 2 (1995): 125-39. Print.

----. Luminous Passage: The Practice and Study of Buddhism in America. Berkeley: University of California Press, 1999. Print.

----. "Pursuing an American Buddhism." Interview by Linda Heuman. Tricycle 2012: 68+. Print.

----. "Trungpa, Chögyam." American national biography (1999): 879-80.

----. "Two Buddhisms Reconsidered." The Buddhist Studies Review 10.2 (1993): 187206. Print.

Prebish, Charles S, and Kenneth K. Tanaka. The Faces of Buddhism in America. Berkeley: University of California Press, 1998. Print.

Prebish, Charles S, and Martin Baumann. Westward Dharma: Buddhism Beyond Asia. Berkeley: University of California Press, 2002. Print.

Rahula, Walpola. History of Buddhism in Ceylon: The Anuradhapura Period, 3d Century Bc-10th Century Ad. Colombo: M. D. Gunasena, 1966. Print.

Rawlinson, Andrew. The Book of Enlightened Masters: Western Teachers in Eastern Traditions. Chicago: Open Court, 1997. Print.

Rawlinson, Andrew. "Western Buddhist Teachers." Western Buddhist Teachers. Web 29 Dec. 2012.

Ray, Reginald A. "And Sparks Will Fly." Interview by Lewis W. Elephant Journal. Winter 2006: 27-36. Print.

----. "Your Breathing Body Volume 1-2: [Audiobook] [Audio CD]." Sounds True

----. Personal interview. 29 Oct. 2012.

Seager, Richard H. Buddhism in America. New York: Columbia University Press, 1999. Print.

Smith, Buster G. "American Buddhism: A Sociological Perspective." Diss. Baylor University, 2009. Web.

Smith, Buster G. "Variety in the Sangha: A Survey of Buddhist Organizations in America." Review of Religious Research, 48.3 (2007): 308-17. Web 
Smith, Tom W. "Religious Diversity in America: The Emergence of Muslims, Buddhists, Hindus, and Others." Journal for the Scientific Study of Religion 41.3 (2002): 577-85. Blackwell Publishing. Web.

Smithers, Stuart W. "Spiritual Guide." Encyclopedia of Religion. Ed. Lindsay Jones. 2nd ed. Vol. 13. Detroit: Macmillan Reference USA, 2005. 8708-8715. Gale Virtual Reference Library. Web. 25 Dec. 2012.

Surya, Das. Awakening the Buddha Within: Eight Steps to Enlightenment: Tibetan Wisdom for the Western World. New York: Broadway Books, 1997. Print.

Tanaka, Kenneth K. "Epilogue: The Colors and Contours of American Buddhism." The Faces of Buddhism in America. Ed. Charles S. Prebish and Kenneth K. Tananka. Berkely and Los Angeles: University of California, 1998. 287-98. Print.

----. "Issues of Ethnicity in the Buddhist Churches of America." American Buddhism: Methods and Findings in Recent Scholarship. Ed. Duncan R. Williams and Christopher S. Queen. Richmond, Surrey: Curzon, 1999. 3-19. Print.

Tanaka, Kenneth K. "The Individual in Relation to the Sangha in American Buddhism: An Examination of "Privatized Religion"" Buddhist-Christian Studies 27 (2007): 115-27. University of Hawai'i Press. Web.

Trungpa, Chögyam, and John Baker. Cutting Through Spiritual Materialism. Berkeley: Shambhala, 1973. Print.

Tweed, Thomas A, and Stephen R. Prothero. Asian Religions in America: A Documentary History. New York: Oxford University Press, 1999. Print.

Tweed, Thomas A. "Who Is a Buddhist? Night-Stand Buddhists and Other Creatures." In Westward Dharma : Buddhism Beyond Asia. Ed. Charles S. Prebish and Martin Baumann. Berkeley: University of California Press, pp 17-33

Tworkov, Helen. 1991. "Many is More.” Tricycle: The Buddhist Review, winter 1991, pp.4.

Yaryan, William. "'Big Tent" Buddhism: Searching for Common Ground Among Western and Asian "Buddhisms" More." Web. 16 July 2012.

Wallace, Alan B. "The Spectrum of Buddhist Practice in the West.", in Westward Dharma : Buddhism Beyond Asia. Ed. Charles S. Prebish and Martin Baumann. Berkeley: University of California Press, pp 34-50

Weber, Max, and S N. Eisenstadt. Max Weber on Charisma and Institution Building: Selected Papers. Chicago: University of Chicago Press, 1968. Print. 
Williams, Duncan R, and Christopher S. Queen. American Buddhism: Methods and Findings in Recent Scholarship. Richmond, Surrey: Curzon, 1999. Print.

Woodhead, Linda. Religions in the Modern World: Traditions and Transformations. London: Routledge, 2002.

Wylie, Turrell V. "Etymology of Tibetan: Bla Ma." Central Asiatic Journal 21 (1977): 145-48. Web. 